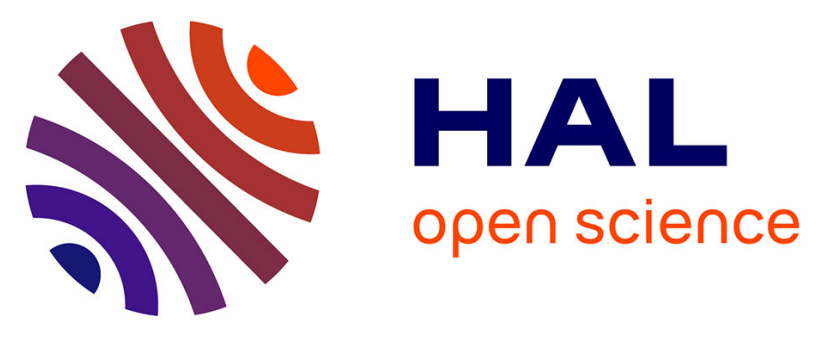

\title{
Participatory Management of Protected Areas for Biodiversity Conservation and Social Inclusion
}

Jean-Pierre Briot, Marta de Azevedo Irving, José Eurico Vasconcelos Filho, Gustavo Mendes de Melo, Isabelle Alvarez, Alessandro Sordoni, Carlos José

Pereira de Lucena

\section{To cite this version:}

Jean-Pierre Briot, Marta de Azevedo Irving, José Eurico Vasconcelos Filho, Gustavo Mendes de Melo, Isabelle Alvarez, et al.. Participatory Management of Protected Areas for Biodiversity Conservation and Social Inclusion: Experience of the SimParc Multi-Agent Based Serious Game. Diana F. Adamatti. Multi-Agent Based Simulations Applied to Biological and Environmental Systems, IGI Global, pp.295-332, 2017, Advances in Computational Intelligence and Robotics (ACIR) Book Series, 978-1-5225-1756-6. hal-01359644v3

\section{HAL Id: hal-01359644 \\ https://hal.sorbonne-universite.fr/hal-01359644v3}

Submitted on 2 May 2017

HAL is a multi-disciplinary open access archive for the deposit and dissemination of scientific research documents, whether they are published or not. The documents may come from teaching and research institutions in France or abroad, or from public or private research centers.

$$
\text { Copyright }
$$

L'archive ouverte pluridisciplinaire HAL, est destinée au dépôt et à la diffusion de documents scientifiques de niveau recherche, publiés ou non, émanant des établissements d'enseignement et de recherche français ou étrangers, des laboratoires publics ou privés. 


\section{Participatory Management of Protected Areas for Biodiversity Conservation and Social Inclusion Experience of the SimParc Multi-Agent Based Serious Game}

Jean-Pierre Briot

Sorbonne Universités, UPMC Univ Paris 06, CNRS, Laboratoire d'Informatique de Paris 6, Paris, France \& DI, PUC-Rio, Rio de Janeiro, Brazil

Marta de Azevedo Irving

EICOS Program, UFRJ, Rio de Janeiro, Brazil

José Eurico Vasconcelos Filho

UNIFOR, Fortaleza, Brazil

Gustavo Mendes de Melo

EICOS Program, UFRJ, Rio de Janeiro, Brazil

Isabelle Alvarez

IRSTEA, LISC, Aubière, France \& Sorbonne Universités, UPMC Univ Paris 06, CNRS, Laboratoire d'Informatique de Paris 6, Paris, France

Alessandro Sordoni

U. Montréal \& Maluuba, Canada

Carlos José Pereira de Lucena

DI, PUC-Rio, Rio de Janeiro, Brazil

\section{ABSTRACT}

The objective of this paper is to reflect on our experience in a serious game research project, named SimParc, about multi-agent support for participatory management of protected areas for biodiversity conservation and social inclusion. Our project has a clear filiation with the MAS-RPG (Multi-AgentSimulation - Role-Playing Games) methodology developed by the ComMod action-research community about participatory management of renewable resources, where multi-agent simulation (MAS) 
computes the dynamics of the resources and role-playing game (RPG) represents the actions and dialogue between stakeholders about the resources. Meanwhile, we have explored some specific directions, such as: dialogue support for negotiation; argumentation-based decision making and its explanation; technical assistance to the players based on viability modeling. In fact, in our project multiagent based simulation focuses on the negotiation process itself, performed by human players and some artificial participants/agents, rather than on the simulation of the resources dynamics. Meanwhile, as we will see, we have also reintroduced the modeling of the socioecosystem dynamics, but as a local technical assistance/analysis tool for the players and not as a global system modeling. In this proposed chapter, we aim at discussing the rationales for these specificities and for the whole project, as well as summarizing the architecture of our prototype system, current results and experience produced and, last but not the least, lessons learned and prospects for future works.

Keywords: Multi-Agent Systems, Agents, Modeling, Simulation, Serious Games, Role Playing Games, Participatory Management, Biodiversity Conservation, Protected Areas, Negotiation, Decision, Argumentation, Viability.

\section{INTRODUCTION}

A significant challenge involved in biodiversity conservation is the management of protected areas (ex: national parks, marine reserves, biosphere reserves... - the main focus of this work being national parks), which usually undergo various pressures on resources use and access, resulting in many conflicts. Methodologies intending to facilitate participatory management and conflict resolution are being addressed via bottom-up approaches that emphasize the role of social actors (stakeholders) involved in these conflicts. Examples of social actors are: park managers, representatives of local communities at the border area, tourism operators, public agencies and nongovernmental organizations (NGOs). Examples of inherent conflicts connected with biodiversity protection are: irregular occupation, inadequate tourism exploration, water pollution, environmental degradation and illegal use of natural resources. In Latin America, the process of management of protected areas for biodiversity conservation usually takes place through the mediation of institutional arenas of dialogue and conflicts, implemented though a management council (Irving 2006). This council, of a participatory nature, includes representatives of various social actors/stakeholders. They represent and express various perspectives and participate in dialogue, negotiations and decisions about protected areas management.

We are conducting a research project to explore how advanced computer support (distributed role-playing game, simulation, artificial agents, negotiation support, decision support...) can help participatory management of protected areas. The project is named SimParc (which stands in French for "Simulation de gestion participative de parcs") and is based on a serious game. Serious games and role-playing games have indeed received increased attention (Crookall, 2010) as effective approaches for exploration and training, in context but without high costs or risks (Michael, 2006). They are considered as promising pedagogical tools for complex collective decision making processes.

Note that, although our project has a very clear filiation with the well known MAS-RPG (Multi-AgentSimulation - Role-Playing Games) methodology (Barreteau, 2003), developed by the companion modeling (ComMod, by Barreteau et al. (2003)) action-research community about participatory management of renewable resources, we have explored some specific directions, such as: dialogue support for negotiation; argumentation-based decision making and its explanation; technical assistance to the players based on viability modeling. 
The objective of this chapter is therefore to discuss the rationales behind the specificities of our project and detail our design, results as well as prospects for future works.

\section{RELATED WORK}

The ComMod (Companion modeling, see (Barreteau et al., 2003)) community had (and still has) a profound impact on research and methods for participatory management of environmental resources and on multi-agent simulation. More specifically, ComMod is about methods for participatory management of renewable resources, with interaction between natural resources inner processes (e.g., hydrodynamics, animals population evolution...) and the human and social processes of their usage (consumption, control...). They have proposed the combination of multi-agent simulation (MAS) - to represent and compute the dynamics of the natural resources - with role-playing games (RPG) - to represent the dialogue between stakeholders, to explore individual and collective decision strategies about the resources (e.g., actual use, access control, conflict resolution, etc.), see (Barreteau, 2003)). The multi-agent simulation platform Cormas (Le Page et al., 2012) is used to implement the simulation part. In the MASRPG combination, simulation runs are interlaced with the different game steps, thus allowing players to understand the consequences of their decisions/actions and their interrelations with decisions/actions of other players. Initially, and still in most of ComMod projects, RPG is conducted manually or semimanually. Pioneering works, such as JogoMan-ViP by Adamatti et al. (2007) and Simulación by Guyot et al. (2006), have aimed at integrating MAS and RPG, that is providing a support for distributed players (inspired by distributed video games) and interfacing it with the multi-agent simulation, thus leading to a more fluid integration between simulation steps and decision steps. They have also started introducing some artificial agents, as players or as assistants. We have followed on such directions, with some specific objectives and results, as we will see.

\section{APPROACH}

\section{General Objectives}

As explained in the introduction, the objective of our SimParc research project is to explore the use of various computer-related techniques, such as serious games, role-playing games, multi-agent systems, simulation, decision support systems, user interfaces, dialogue systems, argumentation-based systems, viability theory, to help at participatory management of protected areas. It is based on the observation of several case studies in Brazil. However, we chose not to reproduce exactly a real case, in order to leave the door open for broader game possibilities. Our focus (very much inline with ComMod) is indeed on improving the process and not the result. In other words, as we will see, we have an epistemic objective, to help stakeholders at understanding the nature of conflicts and negotiation in the management of protected areas. Current SimParc serious game is not (or at least not yet) aimed at decision support (i.e., we do not expect the resulting decisions to be directly applied to a specific park).

More precisely, the SimParc role-playing game is based on the negotiation process that takes place within the park management council. Each player plays a role (as for each council member). Depending on its role profile and the elements of concerns (e.g., tourism spot, traditional community, endangered species, etc.) in each of the landscape unit (sub-area) of the park, each player will try to influence the decision about the level of conservation for each unit. It is clear that conflicts of interest will quickly emerge (e.g., between a biodiversity conservation ONG and a tourism operator about controlling access to a specific landscape unit populated by endangered species), leading to various strategies of negotiation (and possible conflict resolution, e.g., an agreement about a regulated ecotourism policy). A special role in the game is the park manager. He is an arbiter and decision maker.

\section{Specific Research Objectives}


As we will see, the SimParc project somehow departed from standard ComMod/MAS-RPG approach and it has explored some complementary objectives. Let us go back to the characteristics of the domain. At first, in the Brazilian legislation about national parks, direct use of natural resources is forbidden. Only indirect use, such as e.g., tourism, may be allowed. Also, the park management council is of consultative and not decisionary nature. Thus, as opposed to ComMod cases, there is no direct action by the players on the resources. The focus of the players is thus on identification of conflicts and negotiation. At the end of the negotiation (which does not necessarily lead to a consensus), each player makes a final proposal and the park manager has the role of the final decision maker.

The conduction of the SimParc project and the nature of the serious game prototype that we have constructed reflect this specificity. We have initially focused on the support for dialogue and negotiation between players and not on the modeling and simulation of the evolution of ecosystem resources, as would have been the case in standard MAS-RPG projects. As a result, the project started working on a prototype Web-server-based architecture for distributed role-playing (similar to Simulación by Guyot et al. (2006) and JogoMan-ViP by Adamatti et al. (2007)). We have then explored the following research directions: 1) dialogue support for negotiation; 2) argumentation-based decision making and its explanation; 3) technical assistance to the players. In that sense, the SimParc serious game is a multiagent based simulation of the negotiation process itself, performed by human players and some artificial participants. Meanwhile, as we will see below, we have also reintroduced the modeling of the socioecosystem dynamics, but as a local technical assistance/analysis tool for the players and not as a global system modeling. Let us now summarize these three directions:

1) We have designed and implemented a specialized user-interface for negotiation. It uses rhetorical markers and dialogue filtering/structuring mechanisms (detailed in (Vasconcelos et al., 2009a)). A personal assistant also provides help as well as information about the situation of the player within the discussion and proposals (e.g., affinity and discordance with other players proposals, dominance relations, etc.).

2) We have designed and implemented an artificial agent taking the role of the park manager (Sordoni et al., 2010). Its architecture is dual. The first part models the manager individual decision-making process, deliberating about conservation types for each landscape unit. The second part consists in combining the players votes and the park manager vote, based on an influence function. Note that we have decided to use an argumentation-based framework, as traces of arguments produced for the decision are a basis for the explanation of the decision (to the players).

3) We have designed a viability assistant agent (Wei et al., 2012), based on viability theory by Aubin (1992), which helps a player at analyzing the possible impact of his proposed constraints (desired level of conservation) on the park viability. Our rationale is that defining and negotiating about constraints seems more intuitive for players than expressing global optimization objectives. The viability assistant can provide the player with various viability analysis (viability kernel, capture basin, suggest relaxation of constraints) to help him analyzing the viability of his proposal and negotiating with other players.

\section{Organization of the Chapter}

We will start by introducing the design of the role-playing game, at the heart of our project. This roleplaying game is an abstraction of the discussion and negotiation process taking place between stakeholders representatives within a park management council. We will then briefly introduce the principles of the server-based architecture to support the game. Then, we will successively detail our three specific contributions about: 1) negotiation support; 2) manager automated decision; 3) viability analysis. 
We then present some experimental evaluation of our proposals and discuss future prospects before concluding.

\section{THE SIMPARC GAME}

\section{The Role-Playing Game}

Current SimParc game has an epistemic objective: to help and support each participant discover and understand the various factors, conflicts and the importance of dialogue for a more effective management of parks. Note that this game is not (or at least not yet) aimed at decision support (i.e., we do not expect the resulting decisions to be directly applied to a specific park).

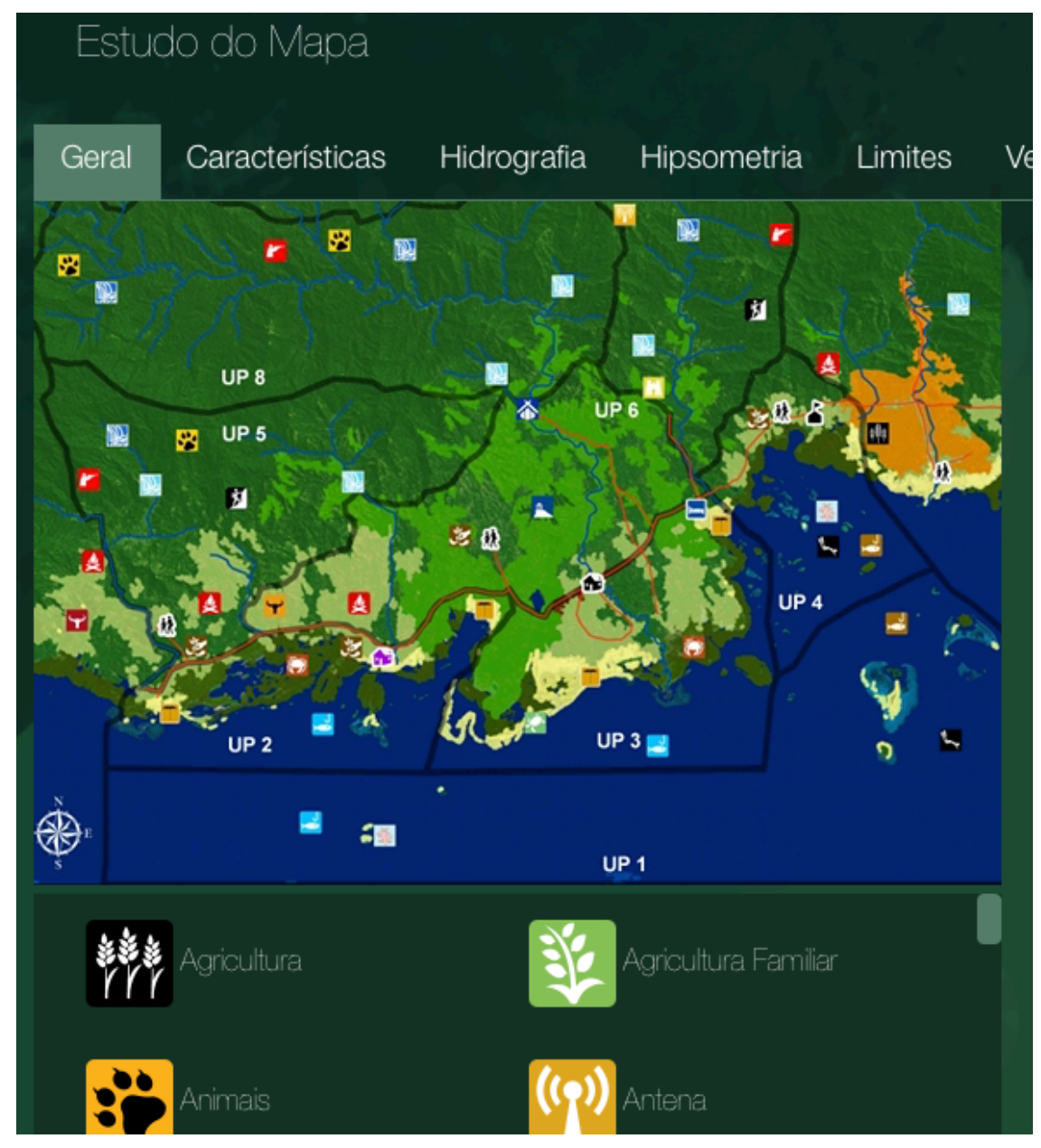

Figure 1. SimParc interface for analyzing the park.

The game is based on a negotiation process that takes place within the park council. This council, of a consultative nature, includes representatives of various stakeholders (e.g., community, tourism operator, environmentalist, non governmental association, water public agency...). The actual game focuses on a discussion within the council about the "zoning" of the park, i.e. the decision about a desired level of conservation for every sub-area of the park (called landscape unit - unidade de paisagem: UP). See at Figure 1 a screen dump of the game showing the representation of the (imaginary) park (with different layers of information: geography, subdivision into landscape units, objects of interest - with the explanation of their pictograms...) and at Figure 2 a focus on one specific landscape unit (UP). 


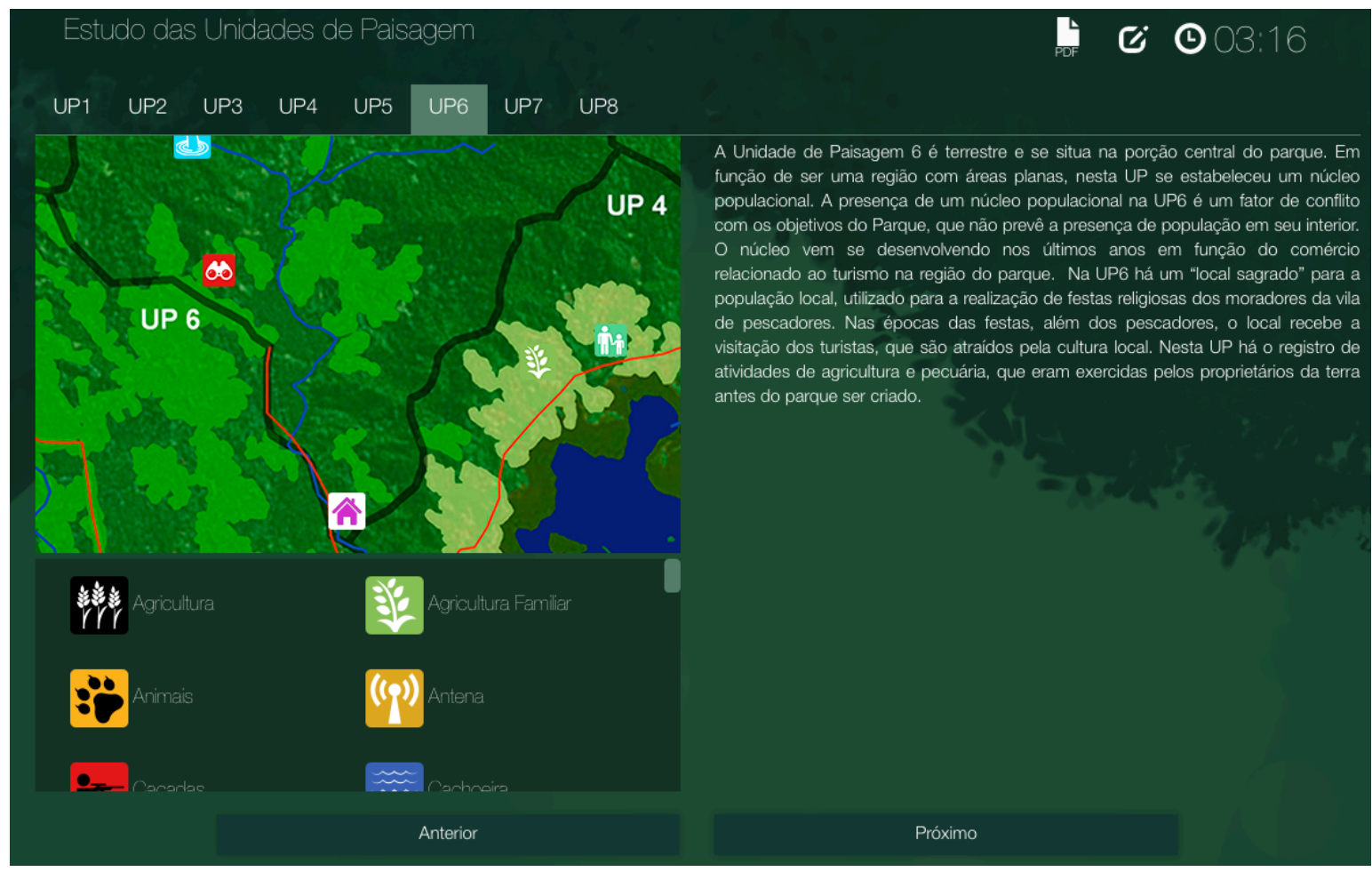

Figure 2. SimParc interface for analyzing a landscape unit (UP).

In the game, we consider nine pre-defined potential levels (that we will consider as types) of conservation, from more restricted conservation to more flexible indirect use of natural resources, as defined by the (Brazilian) legal system. Examples are: "Intangible", the most conservative type, "Primitive" and "Recuperation". Figure 3 shows the interface for a player to decide what type of conservation he will propose for each landscape unit.

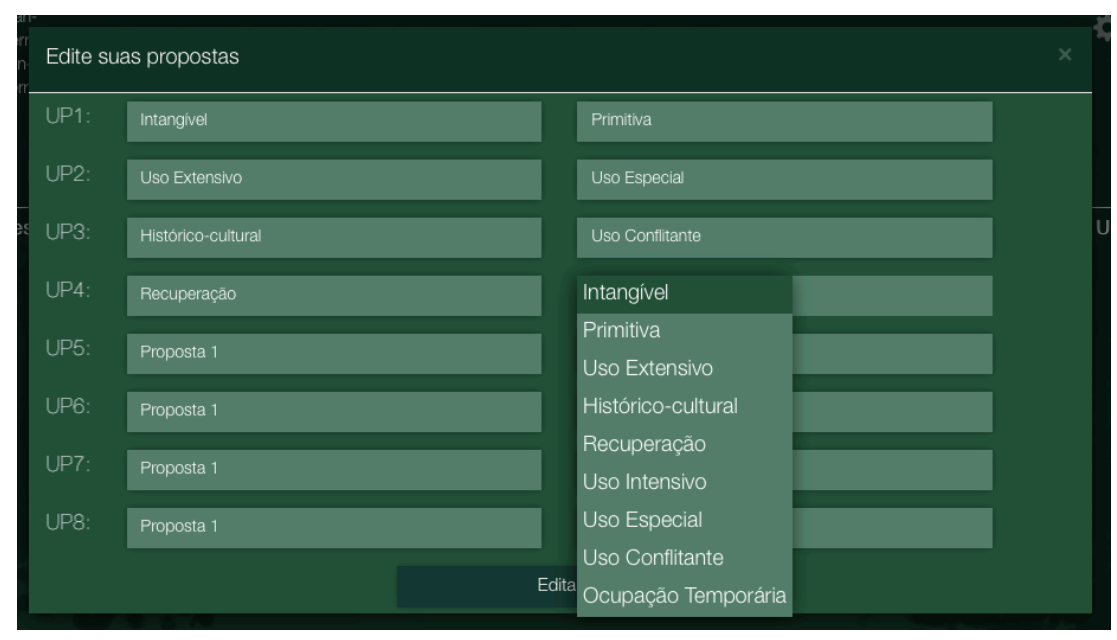

Figure 3. SimParc interface for selecting conservation types.

The game considers a certain number of players' roles, each one representing a certain stakeholder. Each player, as in any role-playing game, has to embody the designed/selected role with its respective background culture, postures and objectives. To facilitate the incorporation of the role by the player, 
SimParc offers a set of personas to represent him/her during the game. Depending on its profile and the elements of concerns (e.g., tourism spot, traditional community, endangered species, cultural attraction... - each type represented by a pictogram) in each landscape unit (see at Figure 2), each player will try to influence the decision about the level (type) of conservation for each landscape unit. Conflicts of interest will quickly emerge, leading to various strategies of negotiation (e.g., coalition formation, trading mutual support for respective objectives, etc).

A special role in the game is the park manager. He is a participant of the game, but as an arbiter and decision maker, and not as a direct player. He observes the negotiation taking place among players and takes the final decision about the levels of conservation for each landscape unit. (It is important to remind that this follows the situation of a real national park in Brazil, where the park management council is only of a consultative nature, thus leaving the final decisions to the manager.) Decision by the park manager is based on the legal framework, on the negotiation process among the players, and on his personal profile (e.g., more conservationist or more open to social concerns) (Irving 2006). He may also have to explain his decision, if the players so demand.

\section{The Game Cycle}

The game is structured along six steps, as illustrated at Figure 4.

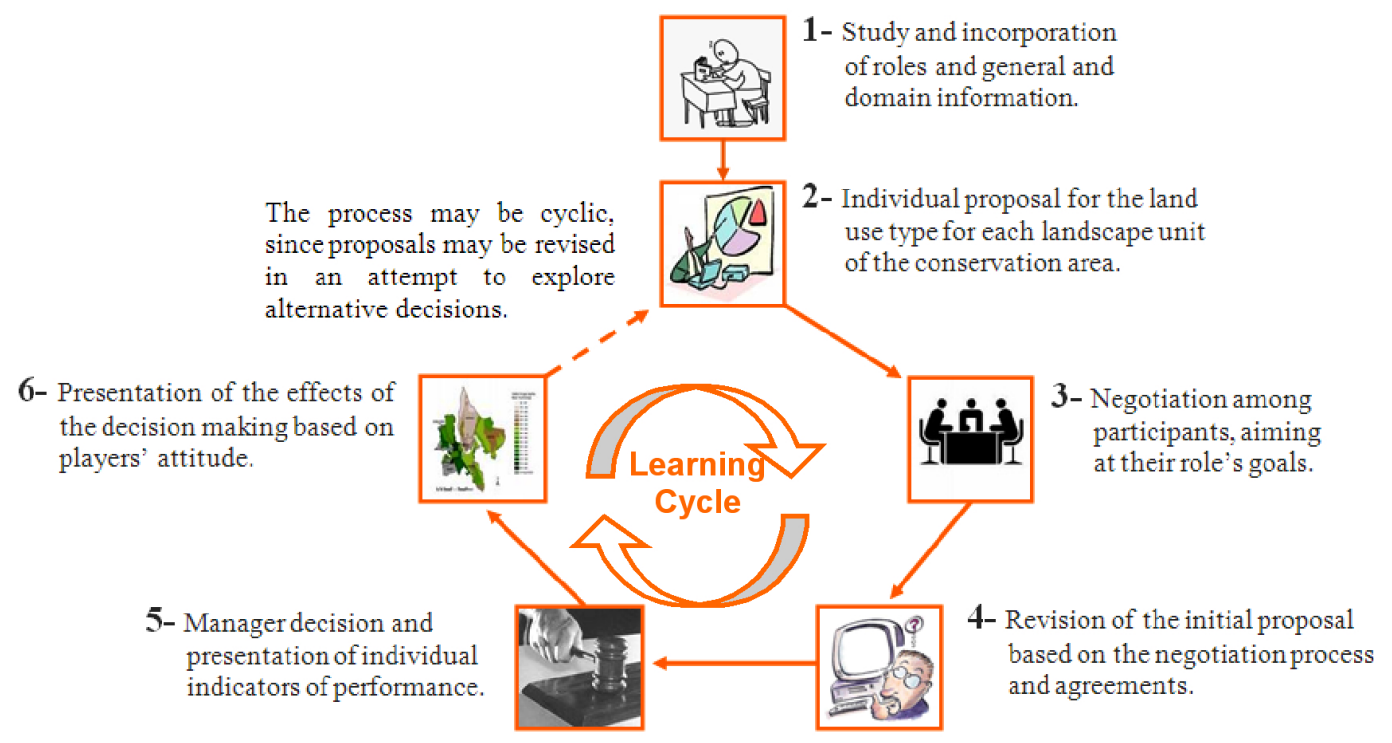

Figure 4. The six steps of the SimParc game.

At the beginning (step 1), each participant is introduced to basic information about the game general context (in an interactive and ludic way, through the metaphorical touring of a conceptual park, see at Figure 5). Then, he is associated with a role (ex: environmentalist, representative of a local community, tourism operator...). Then, an initial scenario is presented to each player, including the setting of the landscape units (see at Figures 1 and 2), the possible types of conservation and the general objective associated to his role. Then (step 2), each player decides a first proposal of types of conservation for each landscape unit (see at Figure 3), based on his/her understanding of the objective of his/her role and his analysis of the situation. Once all players have done so, each player's proposal is made public. 


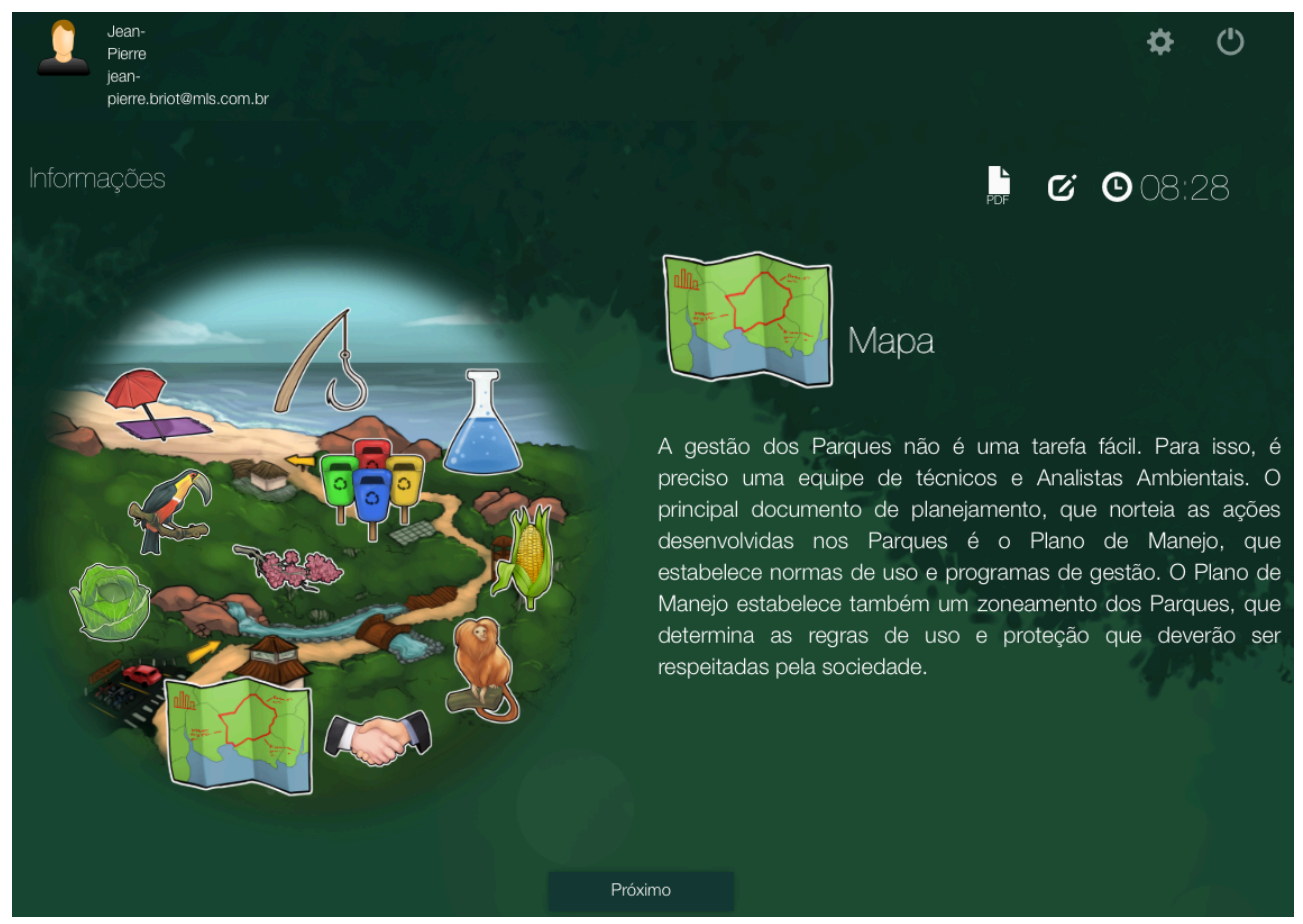

Figure 5. Metaphorical tour for introducing the game.

In step 3, players start to interact and to negotiate about their proposals. This step is, in our opinion, the most important one, because players collectively build their knowledge by means of an argumentation and negotiation process (the interface will be shown at Figure 12). In step 4, they revise their proposals and commit themselves to a final proposal for each landscape unit. In step 5, the park manager makes the final decision, considering the negotiation process, the final proposals and also his personal profile (e.g., more conservationist or more sensitive to social issues). Each player can then consult various indicators of his/her performance (e.g., closeness to his initial objective, degree of consensus, etc.). He can also ask for an explanation about the park manager decision rationales. The last step (step 6) "closes" the epistemic cycle by considering the possible effects of the decision. In the current game, the players provide a simple feedback on the decision by indicating their level of acceptance of the decision.

A new negotiation cycle may then start, thus creating a kind of learning cycle with possibly different allocation of roles to players (so that they play with different objectives and perspectives and thus reflect on the multiplicity of points of view). The main objectives are indeed for participants: to understand the various factors and perspectives involved in decision making and in biodiversity conservation challenges and how they are interrelated; to negotiate; to try to reach a group consensus; and to understand causeeffect relations based on the decisions.

\section{Initial Version}

The initial design of the game (version 1) was conducted during year 2007. It was tested, without any computer support, through a game session conducted in September 2007 (see at Figures 6 and 7, corresponding respectively to the players' analysis phase (step 1) and to the players' negotiation phase (step 3)). There were six roles in the scenario. Each role was played by a team of two players. Players were researchers and students of the APIS research group (which stands for "Áreas Protegidas e Inclusão Social", in English: "Protected Spaces and Social Inclusion"), at UFRJ (Rio de Janeiro), led by Marta Irving, and specialized in biodiversity participatory management. 


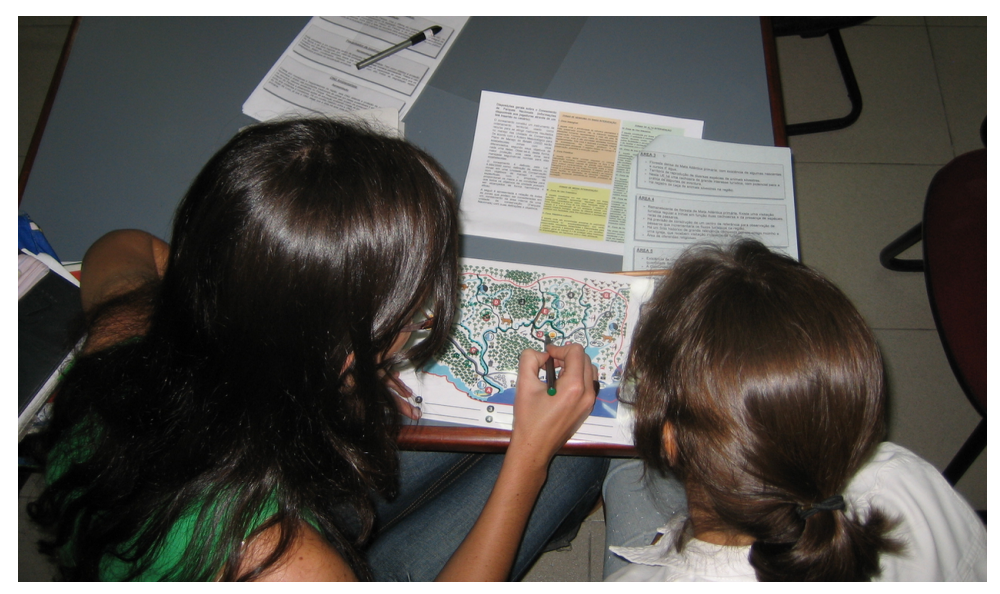

Figure 6. Test of the SimParc game version 1, without computer support-step 1: analysis.

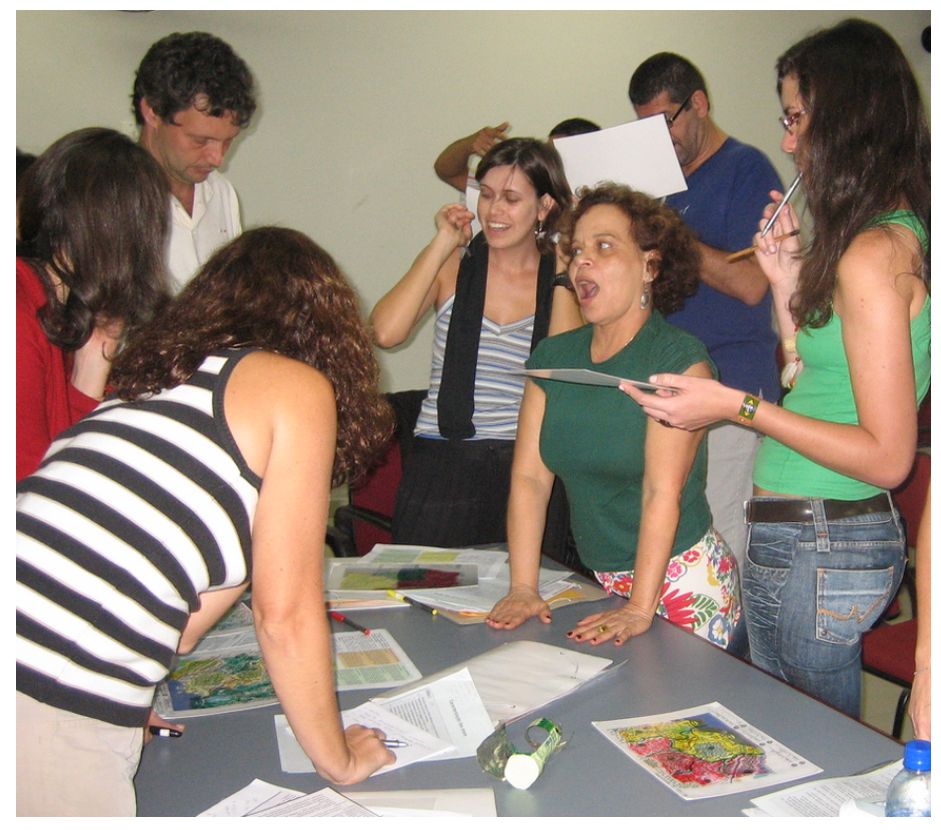

Figure 7. Test of the SimParc game version 1, without computer support-step 3: negotiation.

A first version of the computer prototype was then designed and implemented on top of Simulación, the platform designed by Paul Guyot (2006), as a first proof of concept (Briot et al., 2007). Based on this, we then designed a second version of the prototype, that we will now describe.

\section{THE SIMPARC GAME SUPPORT ARCHITECTURE}

The second version of the prototype benefited from our previous experiences (game sessions and initial prototype) and has been based on a detailed design process. Based on the system requirements, we have adopted Web-based technologies (more precisely Java-based J2EE and JSF) that support the distributed and interactive character of the game as well as an easy deployment. After significant real size testing with specialists of park management issues (which will be described in a forthcoming section about evaluation), we have recently designed and implemented a third version, based on web applications frameworks JRaptor and Spring, as well as responsive Web design (using CSS and HTML handling libraries, in order to make the contents of the system adaptable to any display devices, such as computers, 
tablets, smartphones), more specifically frameworks such as: AngularJS, Html5, CSS3, Bootstrap and jQuery.

Thanks to the Web server approach, it is easy and quick to set up a game session: one just needs for each player a computer or tablet running a web browser and with access to Internet (or to a local network, not necessarily connected outside, as long as it can connect to the Web server). The SimParc Web server to be used may be running on a local computer or on our online server made continuously available.

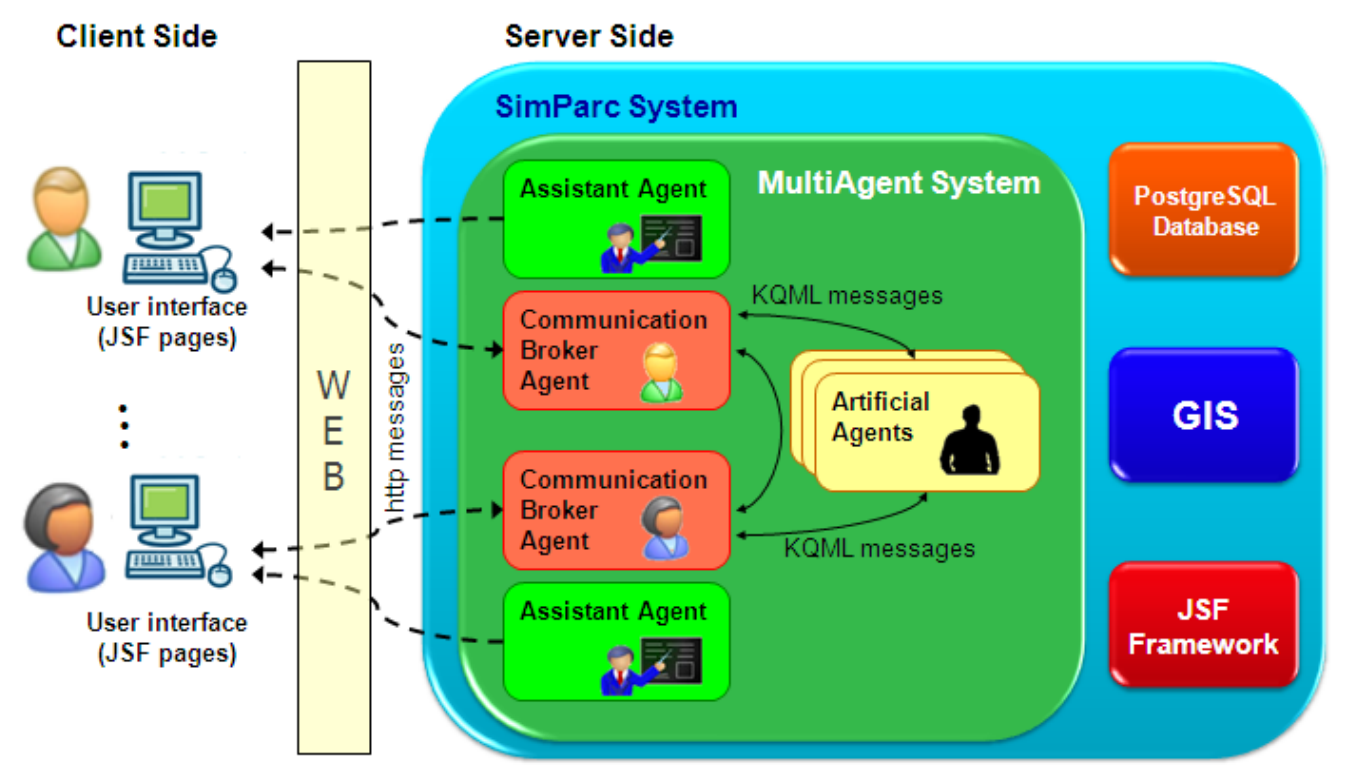

Figure 8. SimParc prototype general architecture.

Figure 8 shows the general architecture and communication structure of SimParc prototype. Distributed users (the players and the park manager) interact with the system mediated internally by communication broker agents (CBA). The function of a CBA is to abstract the fact that each role may be played by a human or by an artificial agent. A CBA also translates user messages in http format into the multi-agent KQML format and vice versa (KQML is a language for interoperability/intercommunication between agents, see (Finin et al., 1994)). For each human player, there is also an assistant agent offering assistance during the game session (see more details in (Vasconcelos 2009b)). During the negotiation phase, players (human or artificial) negotiate among themselves to try to reach an agreement about the type of use for each landscape unit of the park.

A Geographical Information System (GIS) offers to users different layers of information (such as flora, fauna and land characteristics) about the park geographical area (see at Figure 1). All the information exchanged during negotiation phase - namely users' logs, game configurations, game results and general management information - are recorded and read from a PostgreSQL database.

\section{THE INTERFACE}

\section{Design of the Interface}

The interface for negotiation includes specific support for negotiation (rhetorical markers and dialogue filtering/structuring mechanisms, see Vasconcelos et al. (2009a)); access to different kinds of information about other players, land, law; and the help of a personal assistant. Different interfaces are made available depending on the step (phase of the game, ex: analysis, proposal, negotiation) and the needs of the player, 
e.g., analyze the area based in its different layers (e.g., land, hydrography, vegetation..., see at Figure 1), select the desired types of conservation (see at Figure 3), access information, etc.

The process of design has been based on communication-centered design, and its more agile version, eXtreme Communication-Centered Design (Aureliano et al., 2006), design proposals based on the semiotic engineering theory of human-computer interaction. (According to it, both designers and users are interlocutors in an overall communication process that takes place through the interface of the system. Designers must tell users what they mean by the artifact they have created, and users must try to respond to what they are being told (de Souza, 2005)). We have adapted the application of the methodology to the characteristics of the SimParc project.

The output products of the analysis phase are the records from interviews with experts and users, scenarios (use cases), goals diagram and tasks model. The scenarios were constructed based on interviews, in a narrative form, to help at identify contextualized types of usages. The goals diagram (see at Figure 9) was constructed from the scenarios and interviews, with the aim of representing the goals (identified $a$ priori) of the users. We believe that the task model represents an intermediary step, easing a conceptual transition from the analysis phase (what, why and by whom) to the design (how). Note that task models are also widely used and accepted in human-computer interaction (HCI). Overall, the goal of the diagrammatic representation of task models is to provide an overview of the design process for each goal and how these goals are decomposed into tasks and sub-tasks. This diagram provides a new set of information about the process, presenting the hierarchy and flow of tasks, preparing designers and users to an outline of the interaction. We used an adaptation of the Hierarchical Task Analysis (HTA) (Annett et al., 1967) for modeling tasks identified from the goals diagram and the scenarios.

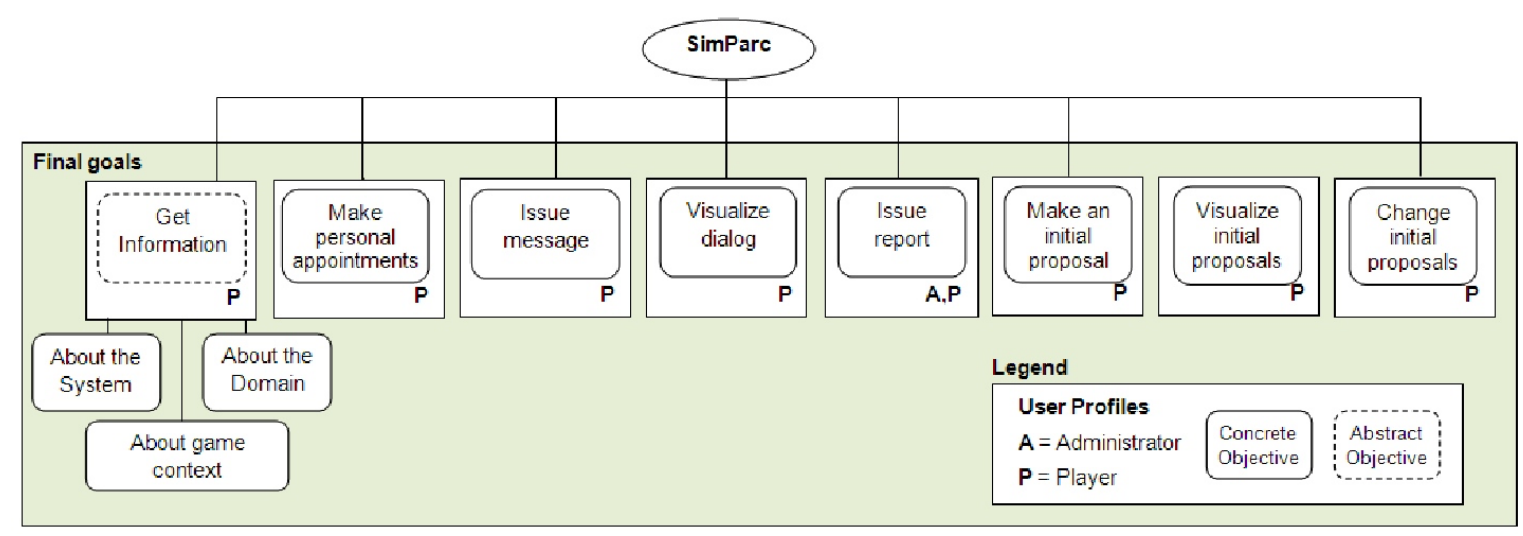

Figure 9. Diagram of final goals.

\section{Design of the Negotiation Language}

We consider negotiation as a particular form of communication process between two or more parties, focused on mutual agreement(s) on a given conflict of interest or opinions (Putnam et al., 1992). We further believe that the adoption of a dialogue language, based on argumentation models and linguistics theory, can offer different ways of support to a computer mediated negotiation process. The main objective for that negotiation language is to find the inflection point between the necessary "framing" and the maintenance of fluidity and naturalness of the dialogue.

The structure of the dialogue is an important factor, because it helps at a better management of the history of the negotiations facilitating the inclusion of artificial agents in the process, increasing the focus on the process, on issues negotiated and on the clarity of dialogue. Many interaction protocols for negotiation 
between agents have been proposed (e.g., via the FIPA-ACL effort, see (FIPA, 2002)), but they privilege the agent-agent communication at the expense of human communication. Note also that computer mediated communication suffers from various types of impoverishment of the dialogue, particularly in relation to non-verbal communication, considering the body language (Ekman, 2007) and the vocal intonation. Thus, we are looking for an intermediate and simple way to promote both human-human and human-agent communication.

We have considered many proposals of notation for structuring and visualization of the argumentation, as, e.g., in (Kirschner, 2003). Among them: the Toulmin model, a reference for the majority of the posterior models; the Issue-Based Information System (IBIS), an informal model based on a grammar that defines the basic elements present in dialogues about decision-making; the "Questions, Options and Criteria" (QOC); the "Procedural Hierarchy of Issues" (PHI) and the "Decision Representation Language" (DRL) (Kirschner, 2003). Based on this analysis, we believe that it is possible to offer a pre-structure, adding to the informal and interpretative characteristic of prose, while maintaining the fluidity of dialogue. Our main inspirations for rhetorical markers is IBIS (Kirschner, 2003), as well as theories of negotiation, e.g., (Wall et al., 1991) (Raiffa, 1982) and Speech Act Theory (Searle, 1969). These markers are basically composed of rhetorical identifiers of intention (see at Figure 10), the object focus of the intention and of a free speech. These elements give the tone of the dialogue, making clear the illocution, and thus facilitating the expression of the desired perlocution (Searle, 1969).

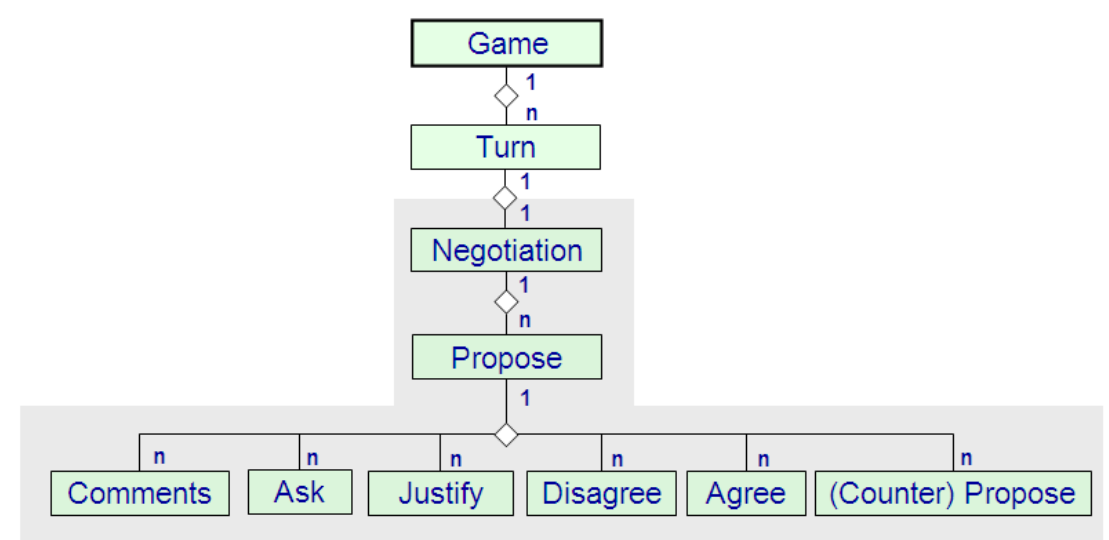

Figure 10. Semi-structure for the text based on rhetorical markers.

We therefore provide the structure by threading from the dialogue, which minimizes risks of losing context, common in computer mediated communication (via chat) (Fuks et al., 2006). Figure 11 shows an example of threading based on the proposed structure. 


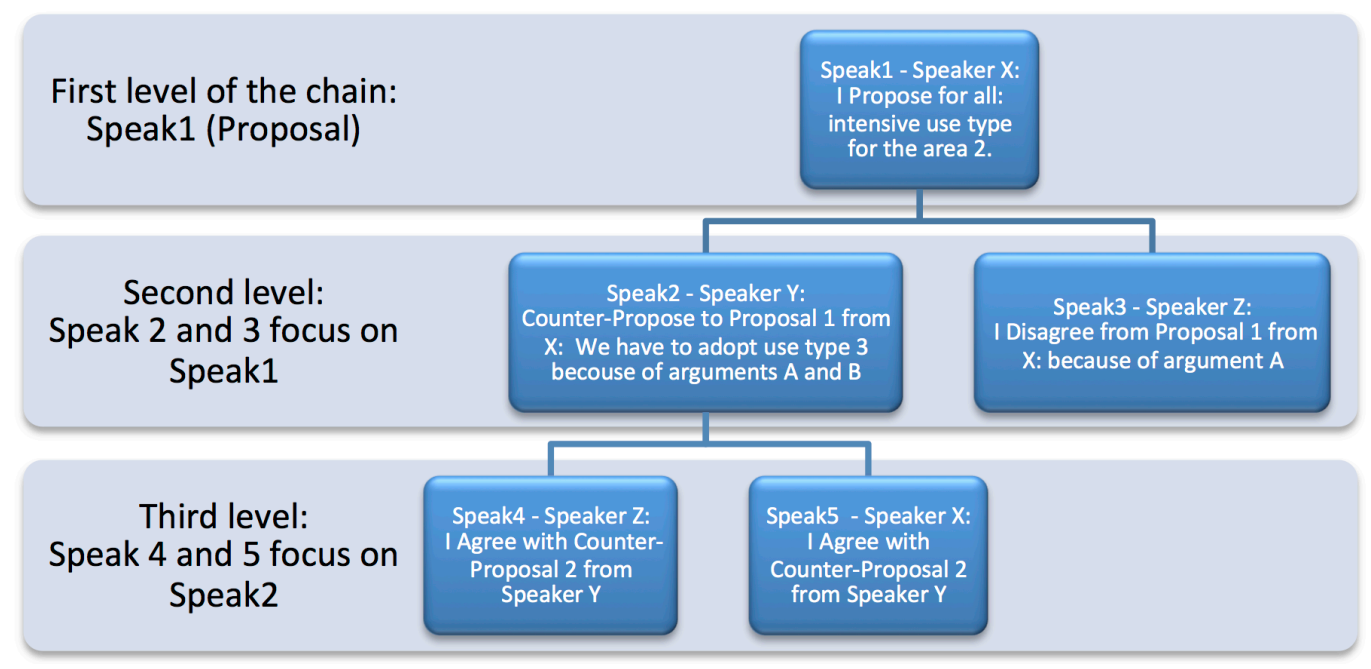

Figure 11. Example of threading structured by the rhetorical markers.

In complement to this semi-structure applied to the text, we propose to model each speak from players as an object. These objects have the following attributes: identifier, sender, receiver(s), marker, focus, and a free text. This modeling eases at the management and indexing of dialogue by the system. For instance, filters may be applied to analyze the history of a dialogue, e.g., filtered along a given speaker, or a specific type of marker. But it also opens the way for its processing by software agents.

\section{Current Interface}

The outputs of the design phase were: interaction diagrams, class diagrams, class and entity relationship model for the database. We then created a first fast prototype in order to evaluate the appearance and usage, before implementing current interface. We have tried to balance a support for some structure of the text of the dialogue and also sufficient fluidity.

We focus here on the interface corresponding to step 3 of the game, i.e., negotiation between players (see at Figure 12). It is indeed a central part of the game, when the shared knowledge is jointly negotiated and built. It includes an area for the history of messages exchanged, which could be presented in chronological order or hierarchical order. It also offers various ways of selecting messages (by intention, topic, player). Another area below contains options for writing and sending messages with rhetorical markers for intention (e.g., propose), the chosen topic (which landscape unit), and the unique or multiple recipients. 


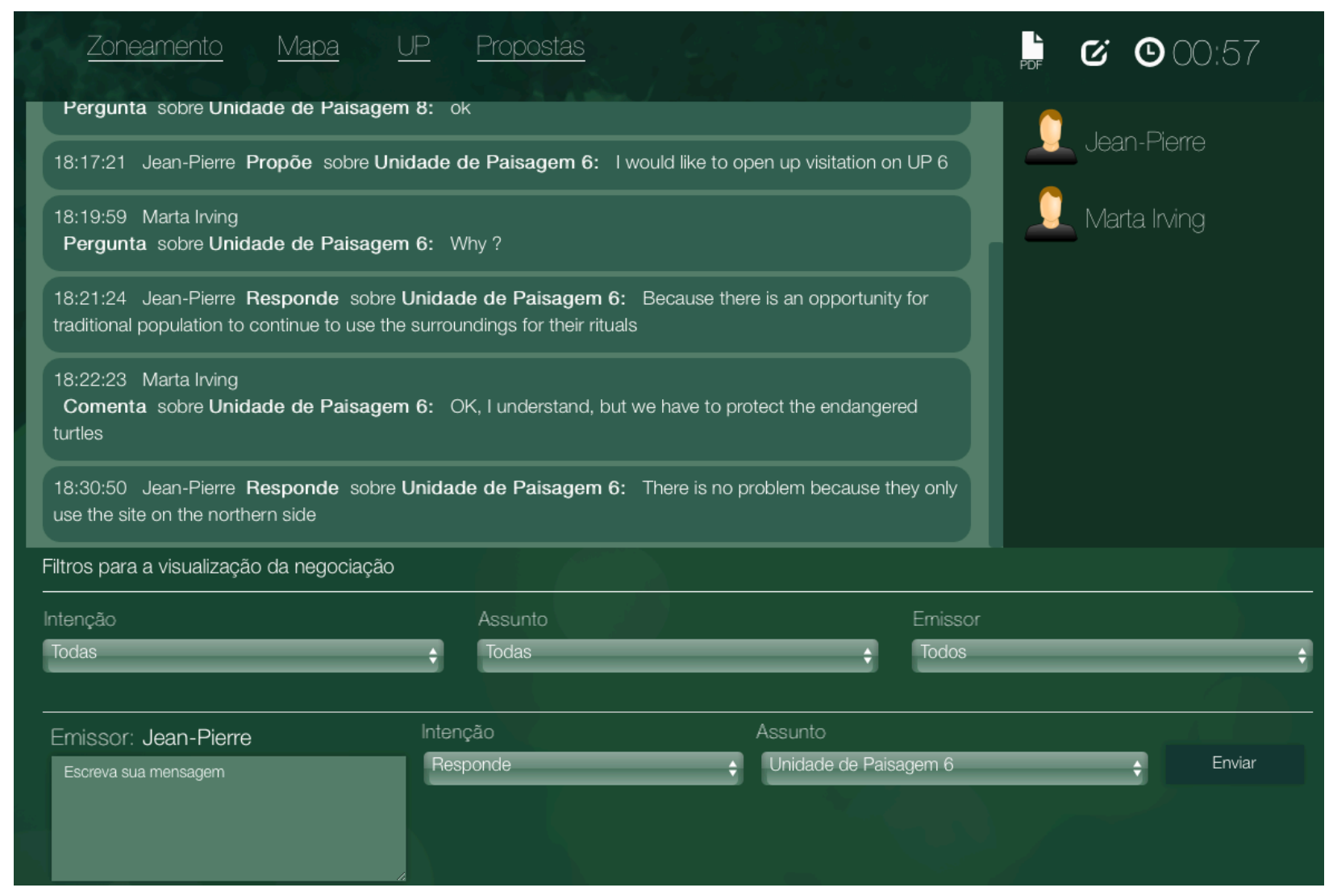

Figure 12. Interface for the negotiation step.

\section{PARK MANAGER AGENT}

As explained earlier, the park manager acts as an arbitrator in the game, making a final decision for conservation levels for each landscape unit. He also explains its decision to all players. The park manager may be played by a human or by an artificial agent. This is set by the game manager when configuring a game session.

The artificial park manager agent current prototype architecture is structured in two phases (see at Figure 13). The first decision step concerns agent's individual decision-making process, deliberating about conservation types for each landscape unit. Broadly speaking, the park manager agent builds its preference preorder over allowed levels of conservation. An argumentation-based framework has been implemented to support the decision making. The key idea is to use the argumentation system to select the desires the agent is going to pursue: natural park stakes and dynamics are considered in order to define objectives for which to aim. Hence, decision-making process applies to actions, i.e. levels of conservation, which best satisfy selected objectives. The second step consists in taking account of players' preferences, with the possibility to adjust the profile of the park managers, from autocratic to democratic, and therefore the influence of players' votes. Therefore, an original method for combining players votes and the park manager vote, based on an influence function, has been designed. 


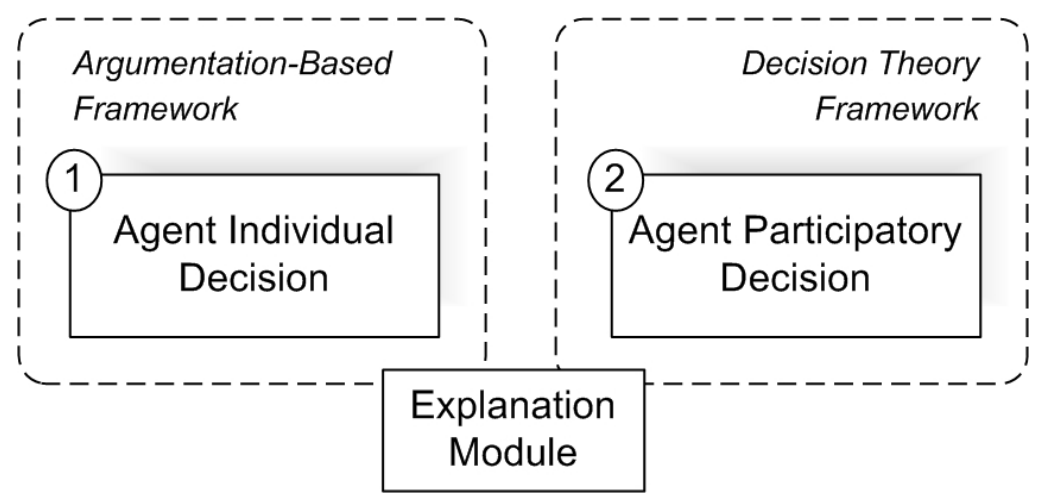

Figure 13. Park manager agent 2 steps decision architecture.

\section{Objectives}

Participatory management aims to emphasize the role of local actors in managing protected areas. However, the park manager is the ultimate arbiter of all policy on devolved matters. He acts like an expert who decides on validity of collective concerted management policies. Moreover, he is not a completely fair and objective arbiter: he still brings his personal opinions and preferences in the debate. Therefore, we aimed at developing an artificial agent modeling the following behaviors:

- Personal preferential profile: Park manager decision-making process is supposed to be influenced by its sensibility to natural park stakes and conflicts. In decision theory terms, we can affirm that park manager's preferential profile could be intended as a preference relation over conservation policies. One of the key issues is to understand that we cannot define a strict bijection between preferential profile and preference relation. Agent's preference relation is partially dependent on natural park resources and realities. Moreover, this relation is not likely to be an order or a preorder. Hence, our agent must be able to generate its preference relation according with its preferential profile. We distinguish two preferential profiles:

- Preservationist: aims to preserve ecosystems and the natural environment.

- Socio-conservationist: generally accepts the notion of sustainable yield - that man can make indirect use of resources from a natural environment on a regular basis without compromising the long term viability of the ecosystem.

- Taking into account stakeholders' decisions: A participatory decision-making leader seeks to involve stakeholders in the process, rather than taking autocratic decisions. However, the question of how much influence stakeholders are given may vary on manager's preferences and beliefs. Hence, our objective is to model the whole spectrum of participation, from autocratic decisions to fully democratic ones. To do so, we want the park manager agent to generate a preference preorder over conservation policies. This is because it should be able to calculate the distance between any two conservation policies. This way, we can merge stakeholders' preference preorders with manager's one to establish one participatory final decision. Autocratic/democratic manager attitude will be modeled by an additional parameter during the merge process.

- Expert decision: The park manager's final decision must consider legal constraints related to environmental management; otherwise, non-viable decisions would be presented to the players, thus invalidating the game's learning objectives. These constraints are directly injected in the cognitive process of the agent. Hence, the agent will determine a dynamic preference preorder over allowed levels of conservation (according to its preferential profile). 
- Explaining final decision: In order to favor the learning cycle, the park manager agent must be able to explain its final decision to the players. We can consider that the players could eventually argue about its decision; the agent should then defend its purposes using some kind of argumentative reasoning. Even if such cases will be explored in future work, it is our concern to conceive a cognitive architecture which provides a good basis for managing these situations.

\section{Architecture Overview}

Let us now present an architecture overview of the park manager agent. As depicted at Figure 13, the architecture is structured in two phases. We believe that sequential decision-making mechanisms can model complex cognitive behaviors along with enhanced explanation capabilities.

The first decision step concerns agent's individual decision-making process: the agent deliberates about the types of conservation for each landscape unit. Broadly speaking, park manager agent builds its preference preorder over allowed levels of conservation. An argumentation-based framework is implemented to support the decision making.

The second step consists in taking account of players' preferences. The result of the execution is the final park manager decision, influenced by the different stakeholder's preferences.

\section{Individual Decision}

Recently, argumentation has been gaining increasing attention in the multi-agent community. Dung's seminal work (Dung, 1995) proposed formal proof that argumentation systems can handle epistemic reasoning under open-world assumptions, usually modeled by non-monotonic logics. Argumentation thus became an established approach for reasoning with inconsistent knowledge, based on the construction and the interaction between arguments. More recently, some research has considered argumentation systems capabilities to model practical reasoning, aimed at reasoning about what to do (Hulstijn \& Torre, 2003) (Amgoud \& Kaci, 2004) (Rahwan \& Amgoud, 2006). Indeed, argumentative deliberation provides a mean for an agent to choose or discard a desire as an intention. Another important motivation for choosing argumentation as a foundation is the capacity of explaining the decisions made. We believe that argumentation "tracking" represents an effective choice for accurate explanations. Conflicts between arguments can be reported to the players, following agent's reasoning cycle, thus enhancing user comprehension.

From this starting position, we have developed an artificial agent on the basis of Rahwan and Amgoud's work (2006). The key idea is to use an argumentation system to select the desires the agent is going to pursue: natural park stakes and dynamics are considered in order to define objectives for which to aim. Hence, decision-making process applies to actions, i.e. levels of conservation, which best satisfy selected objectives. In order to deal with arguments and knowledge representation, we use first-order logic.

Various inference rules were formulated with the objective of providing various types of reasoning capability. Note that the agent's knowledge base is not updated during execution, since it is not directly exposed to social interactions. Knowledge base and inference rules consistency-checking methods are, therefore, not necessary.

The reasoning cycle of the manager agent includes 3 successive phases:

1) reasoning about desires: in order to construct a set of consistent desires (defended by arguments), by managing conflicts between arguments;

2) reasoning about decisions: in order to construct a set of gain vectors (gain for each desire) for each action (type of conservation);

3) multicriteria aggregation: in order to select actions (types of conservation) that best satisfy selected desires, by applying an aggregation operator on gain vectors. 
For example, a simple rule for generating desires from beliefs (i.e. natural park stakes), used during phase 1, is:

$$
\text { Fire } \rightarrow \text { Avoid_Fires, } 4
$$

where Fire (fire danger in the park) is a belief in agent's knowledge base and Avoid_Fires is the desire that is generated from the belief. The value 4 represents the intensity of the generated desire.

Examples of rules for selecting actions (types of conservation) from desires, used during phase 2, are:

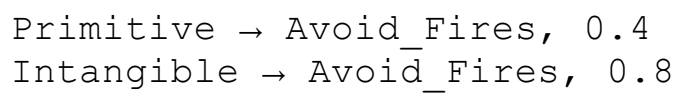

where Primitive and Intangible represent levels of conservation and values 0.4 and 0.8 respectively represent their utility in order to satisfy the corresponding desire (Avoid_Fires). The gain of an action $A$ for a desire $D$ is defined and computed as the product of the utility of $A$ for satisfying $D$ with the intensity of $D$.

During phase 3, the aggregation of gain vectors for each action leads to a single value, measure of its performance. The ordering of the performance of actions (types of conservations) leads to a preference ordering (for the 3 best values), ex such as:

Extensive > Primitive > Intangible

Further details about the architecture may be found in (Sordoni, 2008).

\section{Participatory Decision}

In the real world, a park manager can be more or less participatory, i.e., more or less open to taking into account stakeholders' opinions in his final decision. We propose a method, fitted into the social-choice framework, in which the manager participatory attitude is a model parameter. In a real case scenario, a decision-maker would examine each stakeholder's preferences in order to reach the compromise that best reflects its participatory attitude. Our idea is to represent this behavior by weighting each player's vote according to the manager's point of view. 


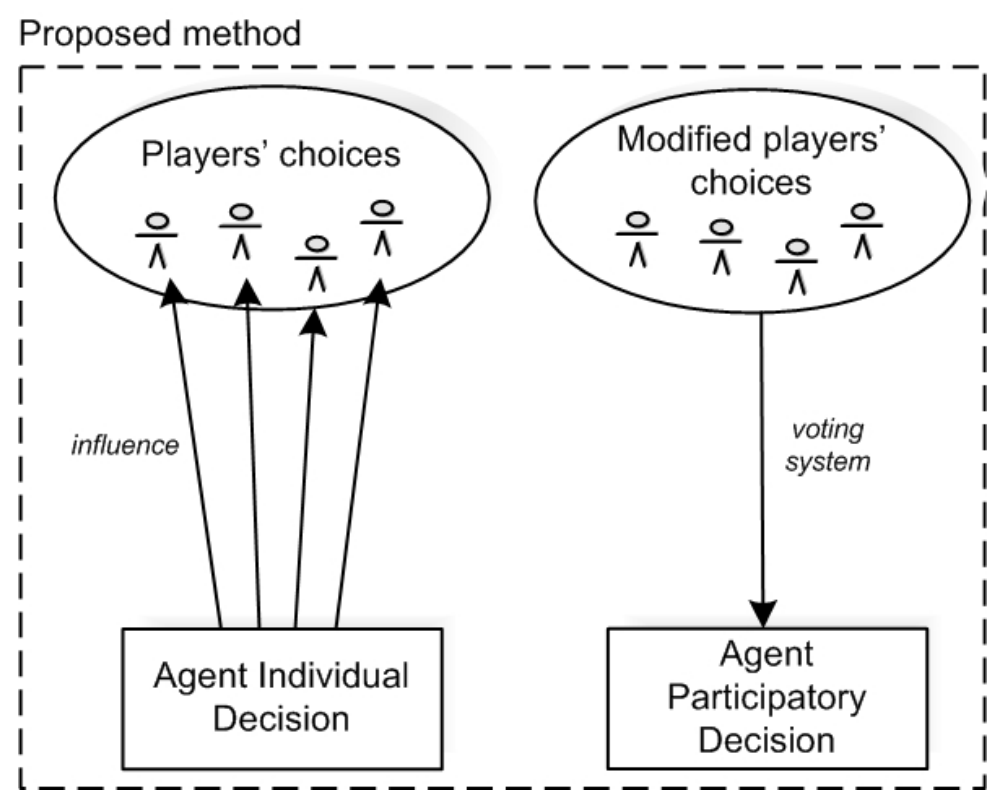

Figure 14. Park manager agent participatory decision architecture.

This concept is illustrated at Figure 14. The process is structured in two phases. Firstly, the manager agent injects its own preferences into the players' choices by means of an influence function describing agent's participatory attitude. Stronger influence translates into more autocratic managers. Secondly, modified players' choices are synthesized, using an aggregation function, i.e. Condorcet voting method. The result of the execution will be the agent participatory decision.

For example, let the following be players' choices, where $>$ is a preference relation $(\mathrm{a}>\mathrm{b}$ means " $\mathrm{a}$ is preferred to b") and $\mathrm{A}=$ \{Intangible, Primitive, Extensive the candidates' set. Players' choices are converted into numeric vectors specifying the candidates' rank (each column corresponds to each of the candidates) for each vote. Suppose that preferences of the $1^{\text {st }}$ player are:

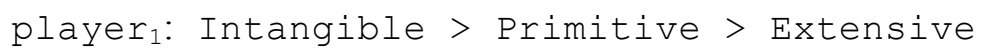

Intangible is the most preferred by player ${ }_{1}$, and thus has the highest rank (3), then Primitive is in $2^{\text {nd }}$ position (2), and Extensive as the last one (1). The corresponding vector of $1^{\text {st }}$ player's preferences is thus:

$$
\mathrm{v}_{1}=(3,2,1)
$$

Suppose now that the $2^{\text {nd }}$ player preferences are:

$$
\text { player } \text { : }_{2} \text { Etensive > Primitive > Intangible }
$$

Intangible is the least preferred by player 2 , and thus has the lowest rank (1), Primitive is in $2^{\text {nd }}$ position (2), and Extensive has the highest rank (3). The corresponding vector of $2^{\text {nd }}$ player's preferences is thus:

$$
\mathrm{v}_{2}=(1,2,3)
$$

Suppose that the preferences of the $3^{\text {rd }}$ player are: 
This leads to the corresponding vector:

$$
\mathrm{v}_{3}=(1,3,2)
$$

Suppose now that the manager individual decision (as produced by previous individual decision module) is:

$$
\begin{aligned}
& \text { manager: Extensive > Primitive > Intangible } \\
& \mathrm{V}_{\mathrm{M}}=(1,2,3)
\end{aligned}
$$

Let the influence function be defined as follows:

$$
f(x, y)=\left\{\begin{array}{cc}
x & \text { if } x=y \\
x * 1 /|x-y| & \text { otherwise }
\end{array}\right.
$$

Modified player's vectors will be:

$$
\begin{aligned}
& \mathrm{mv}_{1}=\left(\mathrm{f}\left(\mathrm{v}_{1}(1), \mathrm{v}_{\mathrm{M}}(1)\right), \mathrm{f}\left(\mathrm{v}_{1}(2), \mathrm{v}_{\mathrm{M}}(2)\right), \mathrm{f}\left(\mathrm{v}_{1}(3), \mathrm{v}_{\mathrm{M}}(3)\right)\right) \\
& \quad=(\mathrm{f}(3,1), \mathrm{f}(2,2), \mathrm{f}(1,3)) \\
& \quad=(3 * 1 /|3-1|, 2,1 * 1 /|1-3|) \\
& \quad=(1.5,2,0.5) \\
& \mathrm{mv}_{2}=(1,2,3) \\
& \mathrm{mv}_{3}=(1,3,2)
\end{aligned}
$$

In order to compute the manager participatory decision, we apply the Choquet integral $C_{\mu}$ (Choquet, 1953) choosing a symmetric capacity measure $\mu(S)=|S|^{2} /|A|^{2}$, where $A$ is the candidates set.

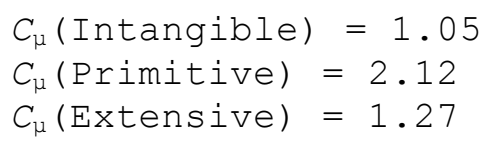

Primitive has the highest value (and Intangible the lowest), thus the final decision will be:

$$
\text { manager_participatory: Primitive > Extensive > Intangible }
$$

\section{From Arguments to Explanations}

As stated above, the chain of arguments are interesting material for explanation of the decisions. In one of our tested scenarios, the manager individual decision is the following:

manager: Intangible > Recuperation

Arguments for Intangible are:

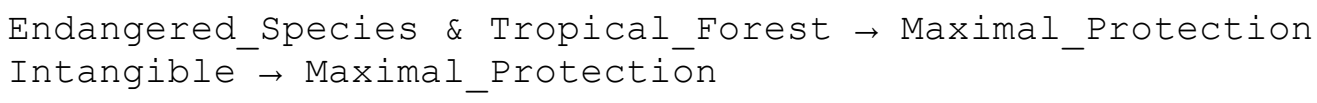


Arguments for Recuperation are:

Fire \& Agriculture_Activities $\rightarrow$ Recover_deteriorated_zone

Recuperation $\rightarrow$ Recover_deteriorated_zone

Note that these traces of arguments represent a basis of explanation of how/why the decision has been made. Meanwhile, making it upto a complete explanation facility remains as a future work.

\section{Implementation Framework}

The architecture presented in this paper has been implemented in the Jason multi-agent platform (Bordini et al., 2007). Besides interpreting the original AgentSpeak(L) language, thus disposing of logic programming capabilities, Jason also features extensibility by user-defined internal actions, written in Java. Hence, it has been possible to easily implement aggregation methods.

The resulting architecture (Sordini et al., 2010) has been implemented and tested offline and its outputs (decision and arguments) have been validated by our project domain experts. In the current architecture of the artificial park manager, only static information about the park and about the final votes of the players are considered. We are considering exploring how to introduce dynamicity in the decision model, taking into account the dynamics of negotiation among the players (the evolution of player's proposed votes during negotiation).

\section{VIABILITY EXPERT AGENT \\ Technocracy vs Relativism}

Regarding environmental governance and public policies, in our case management of protected areas for biodiversity conservation, we believe that there is some fundamental complementarity, as well as some tension, between the needs for participation of social actors involved (stakeholders) and the needs for a minimal kind of technical expertise to help at evaluate management proposals and decisions. Let's illustrate this as follows. On the one hand, a pertinent decision taken without any consultation may not be well accepted by stakeholders because seen as too technocratic and autocratic. (For this reason, we designed an artificial park manager with an adjustable level of incorporation of players proposals). On the other hand, a completely democratic and consensual decision could be very inappropriate regarding the future of the protected area. Furthermore, it is important to note that the technical tools for evaluation and decision making are usually only in the hands of the technical expert(s) or/and the decision maker(s). The potential limits of participation is therefore that the discussion between members of the management council may reach some limits because of the difficulty to analyze and compare (commensurate) the pros and cons of their respective perspectives and proposals. This may lead to blockage and frustration. On a more epistemological and political perspective, we believe that pure participation without any means for minimal grounded technical expertise raises the issue of the incommensurability of proposals (in other words, relativism), thus leaving unclear on what ground a decision could be finally taken (persuasion, trading mutual support for respective objectives, lobbying, coalition formation, intimidation, and in extreme cases force...).

What we propose therefore is to provide the stakeholders/participation with some access to technical tools to self-evaluate and also to self-relate and compare their viewpoints and proposals. Obviously, it is a very ambitious wish and it touches upon some fundamental educational issues. But we believe that with computer-supported recent advances, there are some ways towards empowering stakeholders with more technical expertise, and not let stay this technical expertise only in the hands of the decision makers.

\section{Assistant and Expert Agents}


We envision technical assistance of two kinds. One kind is based on (shallow) decision theory in order to provide players with information about their relative and global positioning within the collective decision process (e.g., relations of dominance and equity properties).

A simplified preliminary version of this kind has already been implemented and tested, in the form of assistant agents to assist players through the game. The basic initial function of these agents is to present and explain each step of the game. During the negotiation step, assistant agents may also provide some helpful information to participants, in order to improve their analysis concerning the negotiation. For instance, different modules inform a player about computed indicators such as affinity (compatibility) with other players proposals (see at Figure 15), participation, influence, as simple indicators of current position of the player within the other players proposals and the collective decision process. It is important to emphasize that the user has total control over his assistant, enabling or disabling it at anytime. Moreover, since we have decided to favor a bottom-up approach, we decided to avoid intrusive assistant agents through the game. We believe that intrusive assistant agents could interfere in the players' cognitive processes. This is why our assistant agents do not suggest decisions to players.

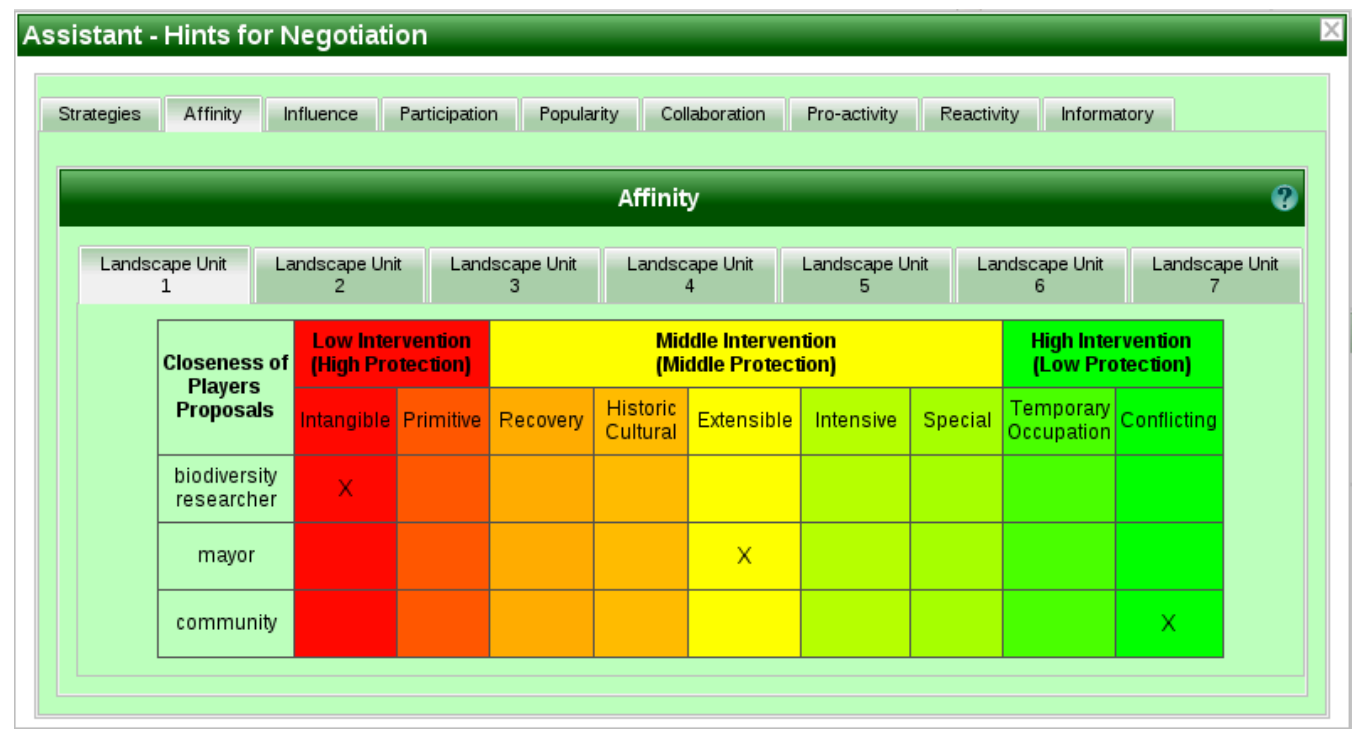

Figure 15. One of the modules (affinity) of the assistant agent.

\section{Viability Theory}

A more ambitious kind of technical expert agent is based on viability theory (Aubin, 1992). It is a mathematical formalism which, as we will see, allows to identify the policies that can retain or restore desirable properties of a dynamical system (biological, economical...) subject to constraints. It has been applied to various domains, including to environment, as for instance for the modeling of lake eutrophication and as a way to analyze viability and resilience properties (Martin, 2002). In our case, the underlying hypothesis is that negotiation between stakeholders could more easily focus on the constraints that each player may want to define (what he considers to be the desirable properties of the park to be viable, e.g., considering the survival of an endangered species, or the sustainability of an economical model of park visitation), rather than on predefined objectives for management decisions. The objective is therefore to provide each player with some technical evaluation of the impact of the constraints he defines as well as the way he could enforce them, in other words, the feasibility of the constraints and objectives that a player himself defines and wants to negotiate. 
Viability theory considers a dynamical system subject to constraints in the state space with the assumption that its evolution may be influenced by a control (which may vary in time). Rather than defining criteria for optimality of the system, viability theory considers constraints on the possible values of the variables (e.g., intervals of values), which should be satisfied for the system to be and remain viable. The methods and the tools of viability theory allow to find conditions (states and decisions) for which such operational constraints will be always satisfied and thus progress in a viable and sustainable way. The viability kernel is defined as the set of states of the system for which always exists (at least) a control function which maintains the system within the constraints. The primary method is to determine the viability kernel and algorithms have been developed to compute it (Saint-Pierre, 1994). Figure 16 shows an example of viability kernel. The dark blue part of the figure represents the viability kernel $\mathrm{Viab}(\mathrm{K})$ for the set of constraints $\mathrm{K} . \mathrm{x}_{0}, \mathrm{y}_{0}$ and $\mathrm{y}_{1}$ are initial states verifying the constraints. The green/light trajectory starting from $\mathrm{x}_{0}$ and directed towards the right corresponds to a viable evolution. All other red/dark trajectories correspond to non viable evolutions.

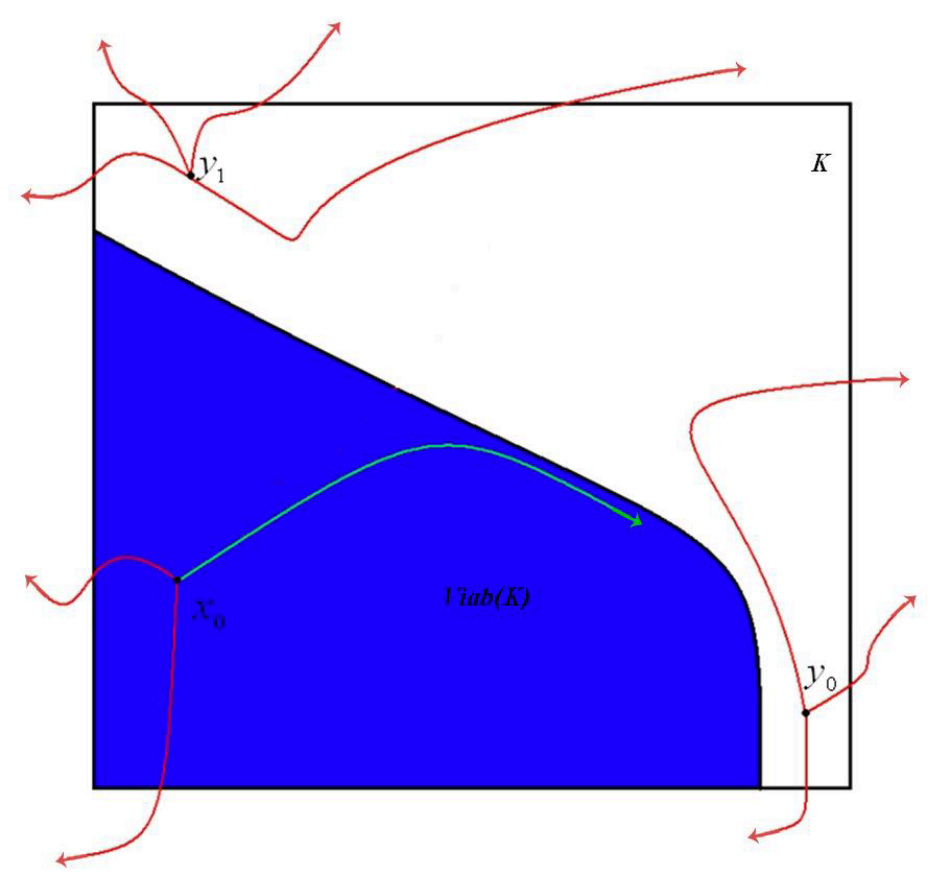

Figure 16. Example of viability kernel.

Another useful study is to analyze the possible trajectories corresponding to a given control strategy in order to see which ones will stay or not within the viability kernel (in other words, analyze if control strategies are viable or not). Figure 17 displays an example of two trajectories. The red/dark trajectory which exits towards the right is obtained with an "empty" strategy with a constant control. The green/light spiral-shape trajectory corresponds to a strategy where the control is variable and adjusted (points correspond to the adjustments of the control values) in order to stay within the viability kernel. Note that it is also possible from current implementation of viability theory to automatically generate a viable control (Aubin et al., 2011). Last, note that there are some other interesting concepts of the viability theory, such as the capture basin (all states for which it exists a control function to reach a given target in some temporal horizon), but we are not (yet) using them as a basis for analysis within our SimParc project. 


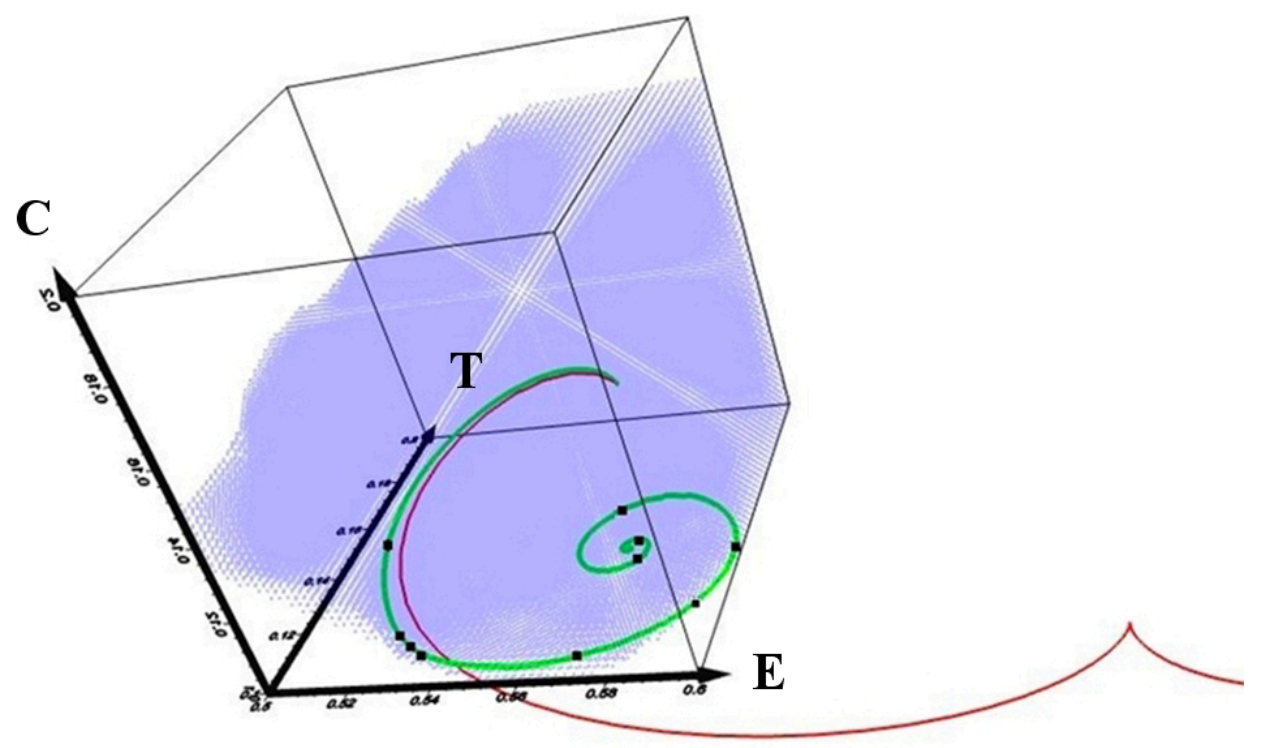

Figure 17. Example of viable and non viable trajectories.

\section{Park Viability}

In summary, viability theory helps at identifying the policies that can retain or restore desirable properties of a dynamical system. It turns out easier to ask the players for desirable properties than for optimization objectives, which are generally not unique and may be unknown for environmental issues. With viability theory, players have to define desirable properties as constraints on the park state variables.

To illustrate the potential of the viability approach, we have chosen a simplified model representing the park environmental and visitation dynamics, with 3 variables: tourists $(T)$, environmental quality $(E)$ and animals (A). It captures the idea of a park sub-area (landscape unit) where tourists come to observe animals (e.g., birds or turtles) in their natural habitat. In addition to these 3 variables, the model also includes a set of parameters: 10 model parameters and one control parameter, introduced as follows:

- Animals (A) develop according to a population evolution law with a maximal growth rate $Y_{A}$.

- The reference value of the carrying capacity $\sigma_{\mathrm{A}}$ represents the environment capacity to host animals (the better is the environment, the higher its capacity).

- The threshold $E_{0}$ is the minimal environment quality value, under which animal reproduction stops.

- Animals may be killed with a probability $\sigma_{T}$ when they encounter a tourist.

- The number of tourists $(\mathrm{T})$ depends on both the attractiveness (quality) of the environment ( $\mathrm{E}$ ) and the number of animals with respective coefficients $\omega_{E}$ and $\omega_{A}$, as well as the number of tourists (they are mutually exclusive with coefficient $\omega_{T}$ - tourists do not like the visitation site to be overcrowded).

- The quality of the environment $(\mathrm{E})$ is described by a classical logistic equation, with a growth rate $Y_{E}$ and a maximal value $K$.

- The environment is damaged by tourists with a rate $\alpha$.

- Finally, $\mathrm{u}$ is the control parameter which represents the investment rate to restore the environment.

The model is defined as follows: 


$$
\begin{aligned}
& A^{\prime}=A^{*}\left(\gamma_{A}\left(\sigma_{A}\left(E-E_{0}\right)-A\right)-\sigma_{T} T\right) \\
& T^{\prime}=T^{*}\left(\omega_{E} E+\omega_{A} A-\omega_{T} T\right) \\
& E^{\prime}=E^{*}\left(\gamma_{E}\left(1-\frac{E}{K}\right)-\alpha T\right)+u(K-E)
\end{aligned}
$$

\begin{tabular}{|c|c|c|c|c|c|c|c|c|c|c|}
\hline$Y_{A}$ & $\sigma_{\mathrm{A}}$ & $E_{0}$ & $\sigma_{T}$ & $\omega_{E}$ & $\omega_{\mathrm{A}}$ & $\omega_{T}$ & $\gamma_{E}$ & $\mathrm{~K}$ & $\alpha$ & $\mathrm{u}$ \\
\hline 1 & 1 & 10 & 0.001 & 0.1 & 3 & 0.1 & 10 & 100 & 0.001 & {$\left[\begin{array}{ll}0 & 0.5\end{array}\right]$} \\
\hline
\end{tabular}

We initialize the parameters with the following default values, shown at Table 1.

Table 1. Default values for the model parameters.

\section{Viability Expert Agent}

We have designed and implemented a prototype viability expert agent based on a viability analysis (Wei et al., 2012). During a game session, each player proposes his set of desirable constraints for each landscape unit (on the three variables $\mathrm{A}, \mathrm{E}$ and $\mathrm{T}$, for instance, a desired maximum number of tourists). A default association between conservation types (Intangible, Primitive,...) and constraints (intervals of values for variables $\mathrm{A}, \mathrm{E}$ and $\mathrm{T}$ ) is proposed to the players and can be adjusted by them. A subset of this table is presented at Table 2.

\begin{tabular}{|l|l|l|l|l|l|}
\hline \multicolumn{1}{|c|}{ Type } & Intangible & Primitive & Cultural & Intensive & Occupation \\
\hline T (Tourists) & 0 & $<200$ & {$[4001500]$} & {$[15003000]$} & {$[01000]$} \\
\hline E (Environment) & $100 \%$ & $>90 \%$ & $>70 \%$ & $>60 \%$ & $>70 \%$ \\
\hline A (Animals) & $100 \%$ & $>95 \%$ & $>85 \%$ & $>80 \%$ & $>85 \%$ \\
\hline
\end{tabular}

Table 2. Default correspondence between conservation types and constraints over variables.

Once a player has entered his desired constraints, the expert agent can compute and visualize the viability kernel corresponding to the player constraints. A player can then use these results as a technical basis for negotiating with other players. If the desired constraints are too strong, the expert agent will compute an empty viability kernel, which means that the park is not viable with the constraints chosen. The expert agent can then propose a relaxation of the constraints. Also the expert agent can help players at analyzing and comparing more than one viability kernel/set of constraints, in order to help players at comparing their strategies and their viabilities.

Suppose that a first player at some point of the game specifies the following constraints (shown at Table 3).

\begin{tabular}{|c|c|c|}
\hline$A_{1}$ & $E_{1}$ & $T_{1}$ \\
\hline$\left[\begin{array}{ll}60 & 80\end{array}\right]$ & {$\left[\begin{array}{ll}60 & 100\end{array}\right]$} & {$\left[\begin{array}{lll}1000 & 2500\end{array}\right]$} \\
\hline
\end{tabular}


Table 3. Set of constraints specified by the $1^{\text {st }}$ player.

The visualization of the corresponding viability kernel by the viability expert agent is shown (in green) at Figure 18(a).

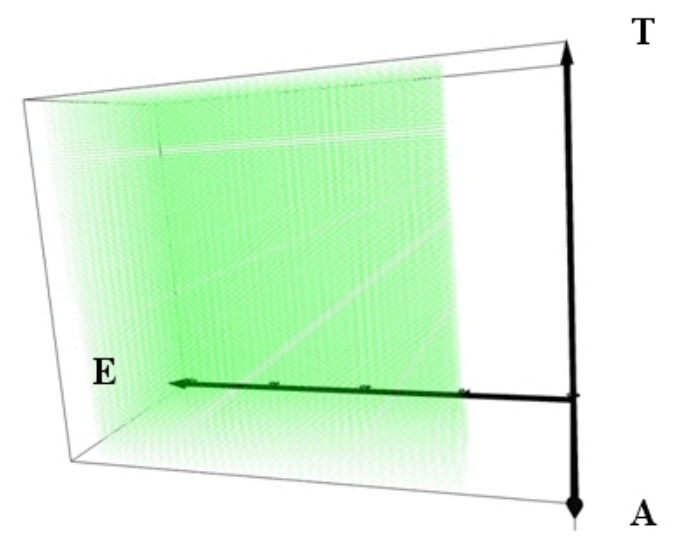

(a)

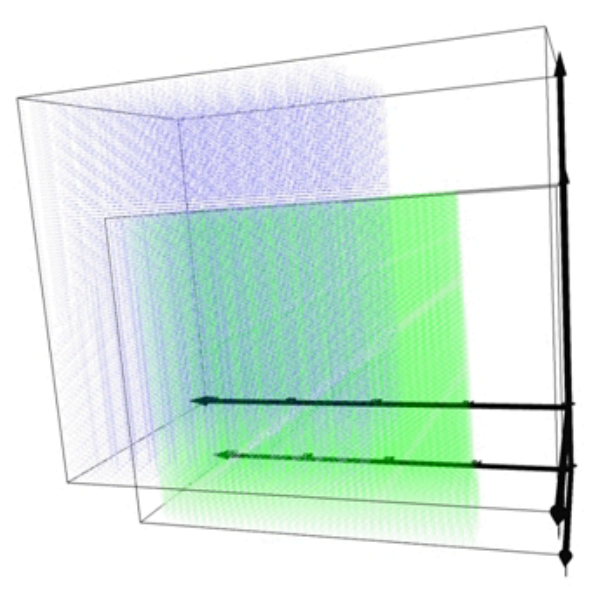

(b)

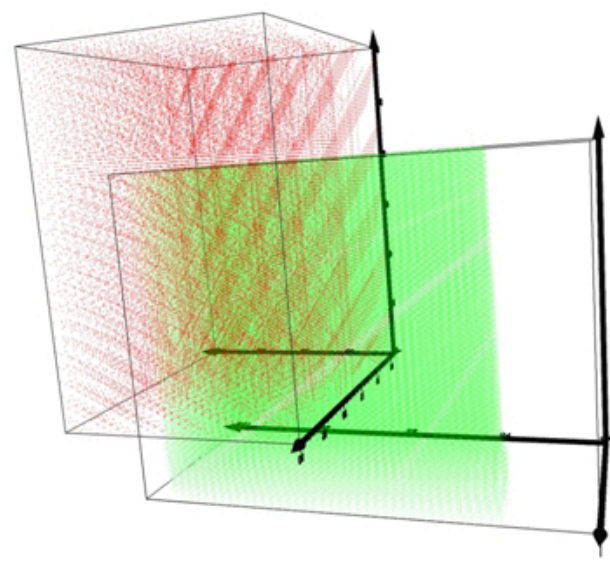

(c)

Figure 18: Examples of viability kernels for the park visitation model: individual and intersections.

Suppose now that this player wants to compare this situation with an alternative (slightly different) set of constraints, shown at Table 4.

\begin{tabular}{|c|c|c|}
\hline $\mathrm{A}_{2}$ & $\mathrm{E}_{2}$ & $\mathrm{~T}_{2}$ \\
\hline$\left[\begin{array}{ll}64 & 90\end{array}\right]$ & {$\left[\begin{array}{ll}60 & 100\end{array}\right]$} & {$\left[\begin{array}{ll}1400 & 3000\end{array}\right]$} \\
\hline
\end{tabular}

Table 4. Alternative set of constraints specified by the $1^{\text {st }}$ player.

Figure 18(b) shows the comparison (and the intersection) of the first viability kernel (in green/right, corresponding to the first set of constraints shown at Table 3) with the second kernel (in blue/left, corresponding to constraints at Table 4). 
Last, suppose that another (second) player is exploring another set of constraints, shown at Table 5, and is currently negotiating with the first player.

\begin{tabular}{|c|c|c|}
\hline$A_{3}$ & $E_{3}$ & $T_{3}$ \\
\hline$\left[\begin{array}{ll}64 & 90\end{array}\right]$ & {$\left[\begin{array}{lll}80 & 100\end{array}\right]$} & {$\left[\begin{array}{lll}1500 & 3000\end{array}\right]$} \\
\hline
\end{tabular}

Table 5. Set of constraints specified by the $2^{\text {nd }}$ player.

Figure 18(c) shows the comparison of the first viability kernel (in green/right, corresponding to the first player's first set of constraints at Table 3) with the viability kernel (in red/left) corresponding to the second player's set of constraints (Table 5). This illustrates the capacity of the viability expert agent to help a player to analyze one viability kernel corresponding to a set of constraints that he himself decided, but also to compare with alternative kernels/constraints explored by himself or proposed by other players during the negotiation. Therefore, this provides the players with a basic way to quantify and analyze the degree of feasibility and viability of proposals. Instead of just comparing the constraint sets, the viability expert compares the viability kernels, which are based on the link between the dynamics and the constraints. Small changes in constraint sets can have a broad range of impacts depending on the dynamics. For example, authorizing lower values for the environment quality would not change the viability kernel from Figure 18(a), since the dynamics cannot guarantee the constraint on animals (A) with relatively high constraints on visitation levels $(\mathrm{T})$ and low levels of environment quality $(\mathrm{E})$. In this case, large changes in environmental constraints have no effect. On the contrary, for higher values of environmental quality $(\mathrm{E})$, small changes can diminish terribly the size of the viability kernel. The main interest of the viability agent, through the computation of the viability kernel, is to show the coupling between the system dynamics and the constraints specified by the player. Furthermore, the comparison of viability kernels may help the player to identify constraints (intervals of values) which are irrelevant because of the system dynamics. For instance, in Figure 18(a), states where value of $E$ is too small are irrelevant because they are unviable, thus it is useless to authorize them.

Once computed and analyzed a viability kernel, a player can also ask the viability expert agent to compute and visualize a possible evolution of the model, by specifying a starting state and the time duration (number of time steps for computing the evolution of the model). Figure 19 shows an example of two trajectories corresponding to two different values of the control parameter $u$ (degree of investment for restoring the environment). The two trajectories start from the same point/state $\mathrm{x}$ within the viability kernel. The green/light trajectory corresponds to a viable trajectory, as it stays within the viability kernel (stops at point/state y). The black/dark trajectory initially follows the green/light trajectory (until point/state y) but exits downwards from the viability kernel and thus corresponds to an unviable trajectory This is because in the second case no viable control (no viable value of investment) has been applied. 


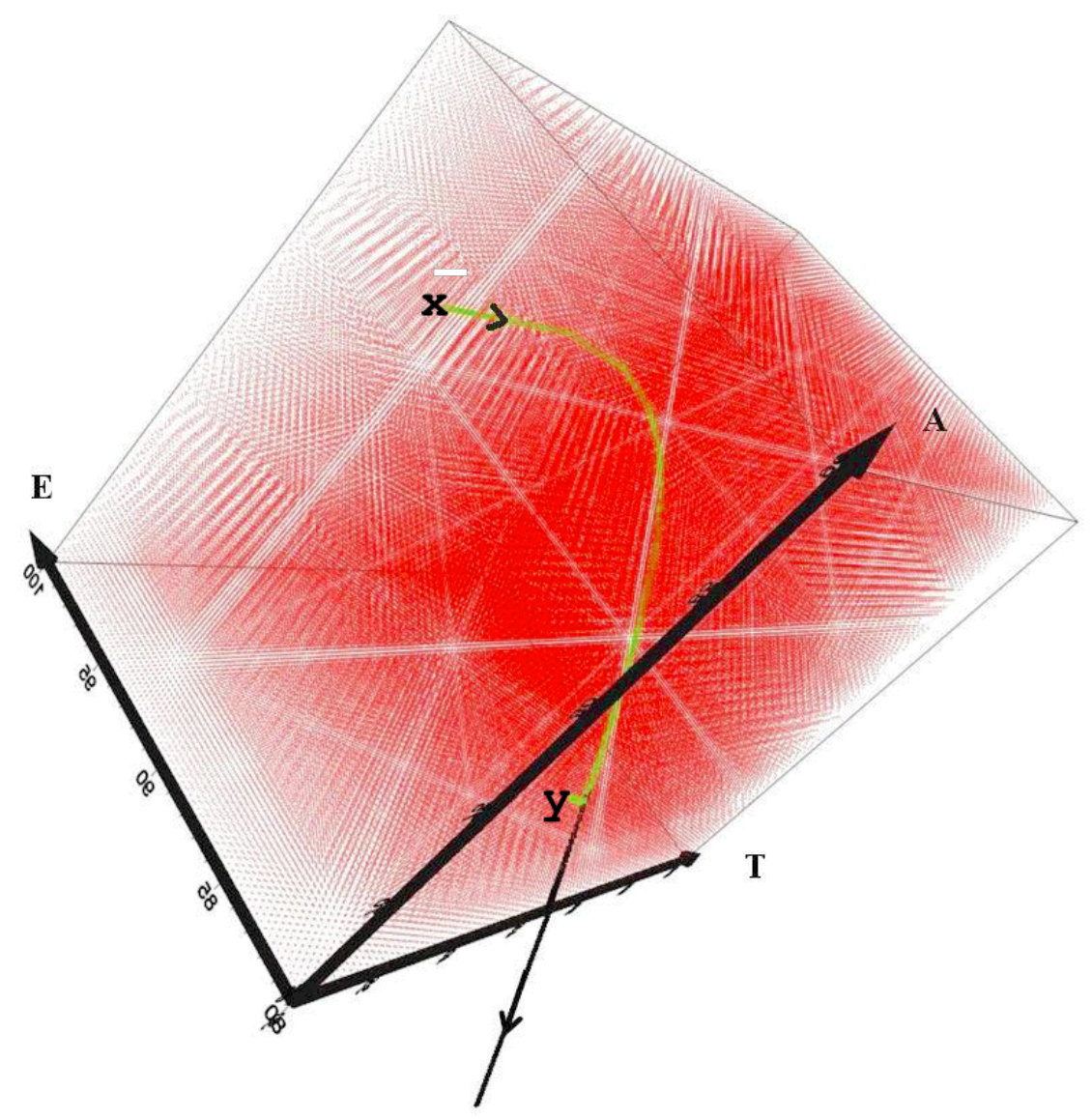

Figure 19. Examples of viable and non viable trajectories for the park visitation model.

In summary, we see that the viability expert agent helps the players to visualize and analyze and also to compare their constraints and their control strategies. This technical evaluation helps them to evaluate the viability of their proposals (constraints as well as control strategies), compare them, and provides them with objective arguments for the negotiation. In order to help the players at handling the informations, an interface for the viability expert agent has been built. It is shown at Figure 20. With this interface, players can:

- $\quad$ select among predefined models;

- define constraints (by entering values intervals);

- select and execute an algorithm to compute the viability kernel;

- analyze the results;

- study the trajectories, i.e. the evolutions. 


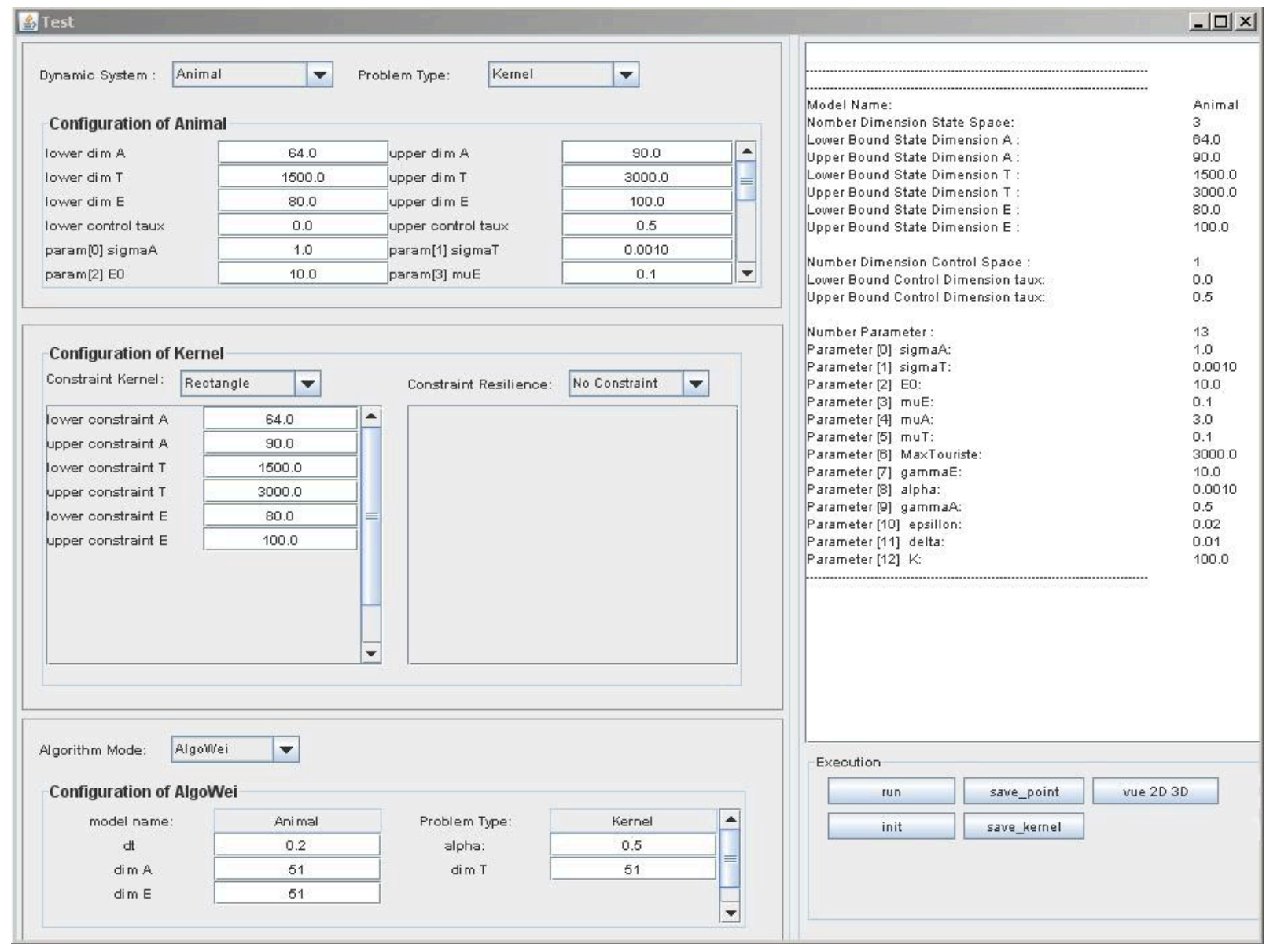

Figure 20. Viability expert agent user interface.

A session of test of the viability expert agent is depicted at Figure 21. Different sessions have been conducted without and with a viability expert agent in order to analyze the benefits of its use (as well as the possible complexity of its use). During the tests conducted, it turned out that it was easier for players to negotiate about constraints than about the types of conservation. It seems that through the viability expert agent, players can analyze and compare their respective desired constraints and their associated viability analysis (see more details about the evaluation of the experiments in (Wei et al., 2012)). Moreover, the expert agent helps players to analyze viable evolutions and control functions. We believe that these results, although preliminary, are promising. 


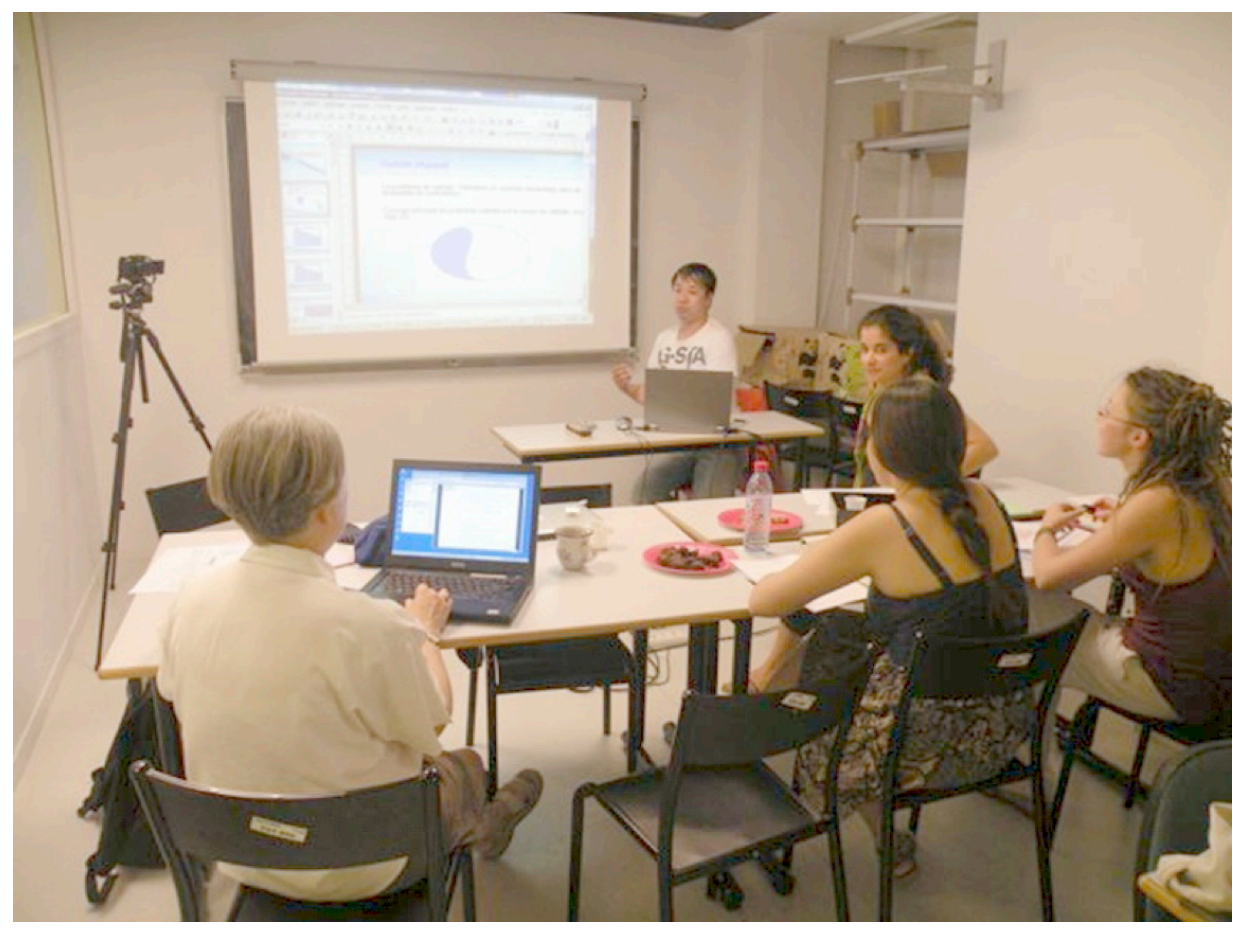

Figure 21. Viability expert test session.

\section{EVALUATION}

The SimParc computer prototype has been tested through numerous game sessions by domain expert players, with debriefing and evaluation. We now report on one of the extensive test sessions and evaluations (with the second version of the prototype). Photos taken during the session are shown at Figures 22 and 23.

The 9 roles of the game and the park manager were played by humans. Almost all players were experts in park management (researchers, students and professionals, either from the public sector or NGOs, also including a professional park manager of Brazil). We also included some players which were not knowledgeable in park management: one experienced in games (serious games and video games) and another one a complete beginner in all aspects.

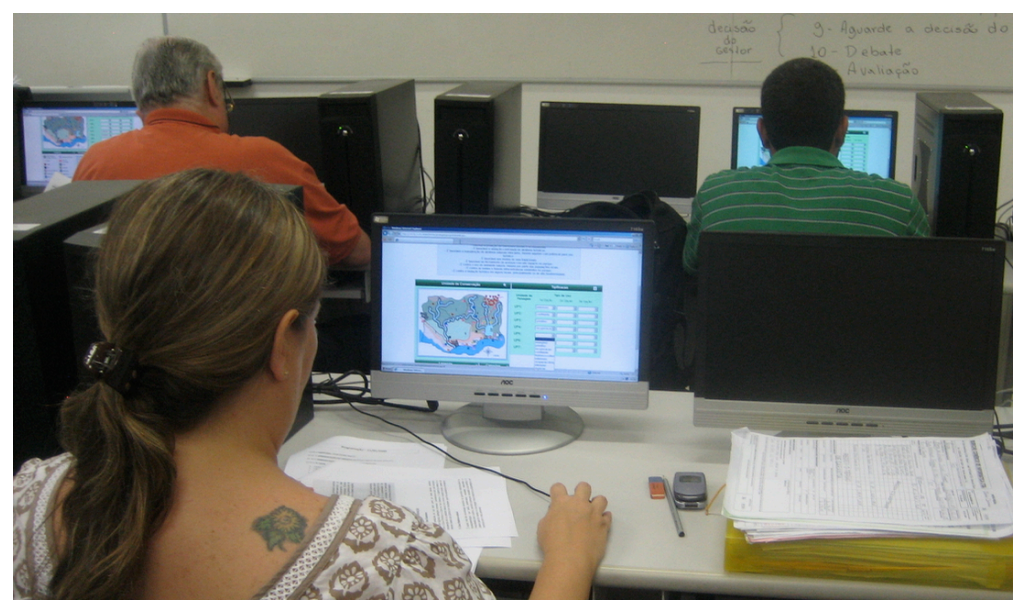


Figure 22. SimParc game session.

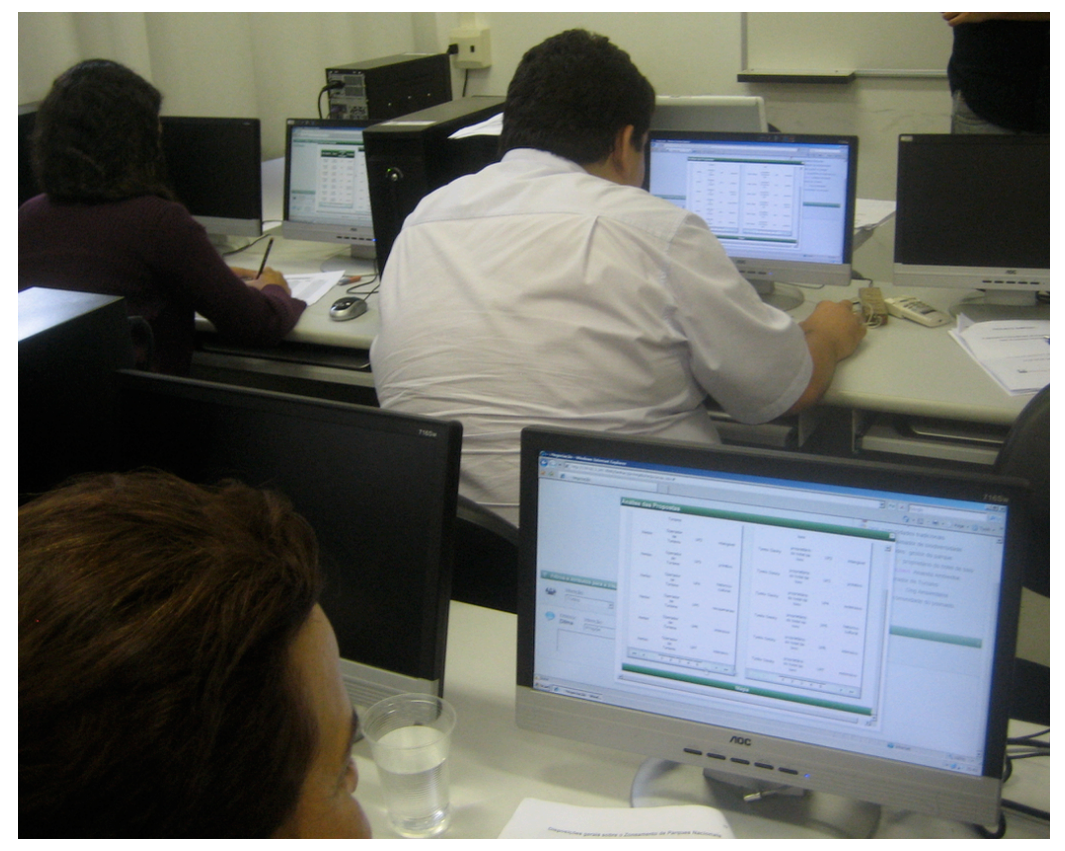

Figure 23. SimParc game session.

Overall, the game was well evaluated by the players. We analyzed data on the game sessions (written questionnaires, recorded debriefing, etc.). Two aspects of the game were positively evaluated by the participants of the game session: the structure, (script, rules and tasks) and contents (scenes, conflicts, environmental management). Through successful integration of structure and content, SimParc was evaluated as a game that reached the goal of creating, in fact, a virtual arena of management. Although the game does not constitute a tool for decision-making directly applicable to real parks, but only a support for epistemic and pedagogical goals, it was highlighted as a positive aspect the closeness of SimParc to a virtual scenario corresponding to the reality of park management, making it more attractive for those people working directly in real parks.

In the analysis of the test, two key aspects to future improvements of the game play were highlighted: information access and interaction. Considering the issue of information access, the evaluation identified the need for improving the conditions for access to content, form, data quality, amount of information available, among others. Regarding the issue of interaction, were mainly considered the resources and tools available to help players negotiate. The information issue is certainly one of the key issues in the SimParc game. For example, it was considered essential that the proposed zoning of each other possible player could always be viewed with decision changes shown in real time, in order for each player to see how others players are defending their interests. The interaction between the players seems also a key element in improving SimParc. Considering that the game requires a continuous and dynamic interaction between players, it has been highlighted the importance of the use of flexible systems with additional features such as hyperlinks to send messages directly to a player and use of tools that allow the creation of parallel trading rooms.

Aiming to investigate whether SimParc is approaching its epistemic and pedagogical goals, participants of the tests were asked about what would be the main goal of the game. The responses were related to the following issues: management practice involving negotiation between different social actors; experiencing different roles to facilitate practicing dialogue and negotiation; illustration of the dynamics 
of conflict; learning environmental expertise and park management; and dissemination of the importance of biodiversity conservation. In the interpretation of the players about if the game had reached such objectives, the players felt that yes, the game was a great exercise for negotiation, stimulating active interaction and interest of players, further encouraged by the possible exchange of roles. Participants also reported that the main knowledge acquired after the game was related to the territorial zoning process of parks, specially for players who did not have advanced knowledge about biodiversity conservation. Players who are professionals about biodiversity conservation explained that they improved their knowledge about the specificities of each type of zoning commonly used in park management. It was also mentioned that the game could be considered as an exercise on process and techniques of negotiation, although the game does not suggest any technique to the players.

Another point that was mentioned refers to the recognition of the diversity of interests in the management of a park. Even though most players knew many of the conflicts illustrated by the game (tension between development demands and conservation issues, distinct perception of nature, etc.), they mentioned that it was possible to improve their analysis based on different roles and groups of social actors that the game illustrates. Last, the fact that the game does not need to be installed as a program on computers, which means greater mobility for applications and larger dissemination of this game, was recognized as an important point.

An interesting finding after the game sessions was also that all players learned and took benefit of the game. The experts explored and refined strategies for negotiation and management, whereas the beginner player took benefit of the game as a more general educational experience about biodiversity conservation and associated issues. In other words, the game appeared to be tolerant to the actual level of expertise of players, an aspect which had not been planned ahead.

A summary of the different test sessions and workshops is available at: http://www-desir.lip6.fr/ briot/simparc/evenements-en.html

\section{PROSPECTS}

We believe that our project, although prospective, has already produced some interesting prototype artifacts, methodological findings and results. Meanwhile, it also opens the way for future works. We will now mention some of them.

\section{Game Server Prototype}

We are currently using the third version (generation) of the SimParc Web server. It has already been tested and updated. We are currently organizing new large scale test sessions in order to evaluate it.

\section{Artificial Players}

Artificial players represent an ongoing research based on previous experiences on virtual players in a computer-supported role-playing game, such as JogoMan-ViP (Adamatti et al., 2007). The objective is to possibly replace some of the human players by artificial agents players. The two main motivations are: (1) the possible absence of sufficient number of human players for a game session; and (2) the need for testing in a systematic way specific configurations of players' profiles, and thus broader possibilities of game experiences. Note that our existing manager agent architecture provides a basis for artificial players decision. We could complement it with the addition of negotiation and interaction modules. The argumentation capabilities could also be used to generate and control the negotiation process. One complementary direction is to use automated analysis of recorded traces of interaction between human players in order to infer models of artificial players. In some previous work (Guyot et al., 2006), genetic programming had been used as a technique to infer interaction models, but alternative induction and machine learning techniques, e.g., inductive logic programming could also be used. 
It is important to note that, as opposed to artificial players in the JogoMan role-playing game (Adamatti et al., 2007), where interaction protocol between players (human or artificial) is simplified and fixed, in our SimParc role-playing game, interactions are not a priori restricted and include arbitrary text. Meanwhile, it is possible to exploit rethorical markers and the choice of preferences by human players to provide artificial players with some useful guidance information. Also, as pointed out above, arguments generated by the actual manager agent architecture provide a good basis for generating negotiation messages, see for instance the work of Amgoud \& Vesic (2012) on the role of argumentation in negotiation dialogues. Furthermore, remember that we do not intend the game to correspond exactly to the situation of an actual park, but to help players at exploring and learning (in an epistemic way) about the participatory process.

\section{Assistant Agents}

As noted above, current implementation of assistant expert agents is preliminary. Expert agents based on decision theory analysis methods may inform a player about his relative as well as global positioning within the collective decision process (e.g., relations of dominance and equity properties).

\section{Viability Expert}

The viability expert is one of the most ambitious direction. This is because it is challenging to combine the inner formalism of viability theory (as well as the complex computations involved) with an intuitive assistance for the human player. The current prototype is therefore more of a proof of concept than a definitive system. Meanwhile, as discussed in the section on the viability expert agent, the preliminary tests that we have conducted have been very positively received by the participants (although the model used was very basic). Also, we need to explore and combine various formal models of the ecosociosystem dynamics to propose a little more realistic evaluation. Therefore, we plan to identify cases of usage conflicts (e.g., between tourism and conservation of an endemic species) and model the dynamics of the system (in an individual-based/multi-agent model or/and in an aggregated model).

Prospects are also to offer more possibilities to the players, such as computing the resilience of the park (i.e., its resistance to perturbation, regarding the issues at stake), as well as suggesting modifications of a given policy in order to improve the resilience. Last, we have recently developed a new implementation framework for viability analysis more flexible and efficient (Alvarez et al., 2016), by representing viability sets with kd-tree data structures (Rouquier et al., 2015), and we will use it for the next version of the viability assistant.

\section{CONCLUSION}

As proposed in the article, the key idea that has inspired us the SimParc project, game and prototype, is to explore methodologies which may help to consolidate democratic forums of decision in cases of protection of nature (Irving, 2006). In this sense, the game intends to be a pedagogical tool to explore and test practices of "good governance" (Graham et al., 2003), one of the major issues for biological biodiversity conventions. Although this is an innovative proposal, with wide application in the present context, the experience has shown that quick and simple solutions to modeling the complexity of this process can become a great risk of loss of meaning of the game. Considering that the game could be (and already has been) played by some professional park managers, it is important to reflect how far the game, that is fun and educational, should be closer to reality and what are the necessary representations and abstractions to achieve the required goals. For example, how the process of negotiating social pacts and democratic management of protected areas can be promoted without losing the focus on respect to real problems and operational by the tax legislation and guidelines for management? Similarly, how to balance technical and scientific expertise in the social participation in the management of biodiversity conservation strategies? Although more evaluation is needed, we believe the feedback gained from the 
different game session tests we conducted is encouraging for the future. We are welcoming any feedback and input from similar or related projects.

More information about SimParc project (papers, tests, workshops...) is available at: http://www-desir.lip6.fr/ briot/simparc/

The authors would like to thank to all the past members of SimParc research team: Altair Sancho, Davis Sansolo, Diana Adamatti, Felipe Martins, Ivan Bursztyn, Lucas Dias, Paul Guyot, Sophie Martin, Vinícius Sebba Patto and Wei Wei, for their contributions to the project. We also thank all the participants of the various game sessions for their participation.

This research has been funded by various programs, such as: ARCUS Program (France), CNRS \& Cemagref Ingénierie Ecologique Program (France), MCT/CNPq/CT-INFO Grandes Desafios Program (Brazil). Some additional individual support has been provided through doctorship or fellowship programs by: French Ministry of Research (France), AlBan (Europe), CAPES, CNPq and FAPERJ (Brazil).

\section{REFERENCES}

Adamatti, D., \& Sichman, S., \& Coelho, H. (2007). Virtual players: From manual to semiautonomous RPG. In F. Barros, C. Frydman, N. Giambiasi and B. Ziegler (Eds.), Proceedings of the AISCMS'07 International Modeling and Simulation Multiconference (IMSM'07), The Society for Modeling Simulation International (SCS), February 2007, pp. 159-164.

Alvarez, I., \& Reuillon, R., \& de Aldama, R. (2016). Viabilitree: A kd-tree Framework for Viability-based Decision. Research report, LIP6, Paris. https://hal.archives-ouvertes.fr/hal01319738

Amgoud, L., \& Vesic, S. (2012). A formal analysis of the role of argumentation in negotiation dialogues. Journal of Logic and Computation, 5(22), 957-978.

Amgoud, L., \& and Kaci, S. (2005). On the generation of bipolar goals in argumentation-based negotiation. In Iyad Rahwan, Pavlos Moraitis, and Chris Reed, (Eds), Argumentation in MultiAgent Systems - Proceedings of the First International Workshop (ArgMAS'04) - Expanded and Invited Contributions, Volume 3366 of Lecture Notes in Computer Science. Heidelberg, Germany: Springer Verlag.

Annett, J., \& Duncan, K. D. (1967). Task analysis and training design. Journal of Occupational Psychology, 41, 211-221.

Aubin, J.-P. (1992). Viability theory. Basel, Switzerland: Birkhäuser.

Aubin, J.-P., \& Bayen, A. M., \& Saint-Pierre, P. (2011). Viability Theory: New Directions. Heidelberg, Germany: Springer Verlag.

Aureliano, V., \& Silva, B., \& Barbosa, S. (2006). Extreme Designing: Binding Sketching to an Interaction Model in a Streamlined HCI Design Approach. Proceedings of the VII Simpósio 
Brasileiro sobre Fatores Humanos em Sistemas Computacionais (IHC'06), Natal, RN, Brazil, November.

Barreteau, O. et al. (2003). Our Companion Modelling Approach. Journal of Artificial Societies and Social Simulation, 6(2), Article 1.

Barreteau, O. (2003). The joint use of role-playing games and models regarding negotiation processes: Characterization of associations. Journal of Artificial Societies and Social Simulation, 6(2), Article 3.

Bordini, R. H., \& Hübner, J. F., \& Wooldridge, M., (2007). Programming multi-agent systems in AgentSpeak using Jason. Chichester, U.K.: Wiley.

Brazil (2000). Lei $N^{\circ}$ 9.985, que regulamenta o Art. 225, parágrafo $1^{\circ}$, incisos I, II, III, VII da Constituição Federal, institui o Sistema Nacional de Unidades de Conservação da Natureza e dá outras providências, Brazil.

Brazil (2002). Decreto No. 4340 que regulamenta os artigos da Lei No. 9985 que institui o Sistema Nacional de Unidades de Conservação - SNUC, Brazil.

Briot, J.-P., \& Guyot, P., \& Irving, M. (2007). Participatory simulation for collective management of protected areas for biodiversity conservation and social inclusion. In F. Barros, C. Frydman, N. Giambiasi and B. Zeigler, (Eds), Proceedings of the International Modeling and Simulation Multiconference 2007 (IMSM'07), The Society for Modeling \& Simulation International (SCS), Buenos Aires, Argentina, pp. 183-188.

Choquet, G. (1953). Theory of capacities. Journal of Fourier Institute, 5, 131-295.

Crookall, D. (2010). Serious Games, Debriefing, and Simulation/Gaming as a Discipline. Simulation \& Gaming, 41(6), 898-920.

de Souza, C.S. (2005). The Semiotic Engineering of Human-Computer Interaction, Boston, MA, U.S.A.: MIT Press.

Ekman, P. (2007). Emotions Revealed - Recognizing Faces and Feelings to Improve Communication and Emotional Life (2nd Edition). New York, NY, U.S.A.: Holt, Henry \& Company, Inc.

Finin, T., \& Fritzon, R., \& McKay, D., \& McEntire, R. (1994). KQML as an Agent Communication language. In Proceedings of the Third International Conference on Information and Knowledge Management (CIKM'94), ACM Press, pp. 456-463.

FIPA (2002). FIPA Agent Communication specifications. Foundation for Intelligent Physical Agents. http://www.fipa.org/repository/aclspecs.html 
Fuks, H., \& Pimentel, M., \& Lucena, C. J. P. (2006). R-U-Typing-2-Me? Evolving a chat tool to increase understanding in learning activities. Computer-Supported Collaborative Learning (ijCSCL), 1, 117-142.

Gerosa, M. A., \& Pimentel, M., \& Fuks, H., \& Lucena, C. J. P. (2006). Development of Groupware Based on the 3C Collaboration Model and Component Technology. In Y.A. Dimitriadis, I. Zigurs, E. Gómez-Sánchez (Eds.), Groupware: Design, Implementation, and Use, LNCS, Vol. 4154, Springer, pp. 302-309.

Graham, J., \& Amos, B., \& Plumptre, T. (2003). Governance principles for protected areas in the 21st century. Durban, South Africa: IUCN (International Union for Conservation of Nature).

Guyot, P., \& Drogoul, A., \& Honiden, S. (2006). Power and negotiation: Lessons from agentbased participatory simulations. In P. Stone and G. Weiss (Eds.), Proceedings of the 5th International Joint Conference on Autonomous Agents and Multiagent Systems (AAMAS'06), Hakodate, Japan, May, pp. 27-33.

Hulstijn, J., \& van der Torre, L. (2003). Combining goal generation and planning in an argumentation framework. In Tom Heskes, Peter Lucas, Louis Vuurpijl, and Wim Wiegerinck, (Eds), Proceedings of the 15th Belgium-Netherlands Conference on Artificial Intelligence (BNAIC'2003), Nijmegen, The Netherlands, October, pp. 155-162.

Irving, M. A. (2006). Áreas Protegidas e Inclusão Social: Construindo Novos Significados. Rio de Janeiro, Brazil: Aquarius.

Kirschner, P. A., \& Shum, J. B., \& Carr, S. C., (Eds.) (2003). Visualizing Argumentation: Software Tools for Collaborative and Educational Sense-Making. Heidelberg, Germany: Springer.

Le Page, C., \& Becub, N., Bommel, P. \& Bousquet, F., (2012). Participatory Agent-Based Simulation for Renewable Resource Management: The Role of the Cormas Simulation Platform to Nurture a Community of Practice, Journal of Artificial Societies and Social Simulation, 15(1), Article 10.

Martin, S. (2004). The cost of restoration as a way of defining resilience: a viability approach applied to a model of lake eutrophication. Conservation Ecology, 9(2), Article 8.

Michael, D., \& Chen, S. (2006). Serious Games Games that Educate, Train and Inform. Thomson Course Technology.

Putnam, L. L., \& Roloff, M. E. (Eds.) (1992). Communication and Negotiation. Newbury Park, CA, U.S.A.: Sage. (Vol. 20, Sage Annual Review Series).

Raiffa, H. (1982). The Art \& Science of Negotiation. Cambridge, MA, U.S.A.: Harvard University Press. 
Rao, A., \& Georgeff, M. (1991). Modelling Rational Agents within a BDI-Architecture. In Proceedings of the 2nd International Conference on Principles of Knowledge Representation and Reasoning, pp. 473-484.

Rahwan, I., \& Amgoud, L. (2006). An Argumentation-based Approach for Practical Reasoning. In Gerhard Weiss \& Peter Stone, (Eds), Proceedings of the 5th International Joint Conference on Autonomous Agents \& Multi Agent Systems (AAMAS'2006), New York, NY, U.S.A.: ACM Press, pp. 347-354.

Rouquier, J.-B., \& Alvarez, I., \& Reuillon, R., \& Wuillemin, P.-H. (2015) A kd-tree algorithm to discover the boundary of a black box hypervolume or how to peel potatoes by recursively cutting them in halves. Annals of Mathematics and Artificial Intelligence, 75(3), 335-350.

Saint-Pierre, P. (1994). Approximation of the viability kernel. Applied Mathematics and Optimization, 29, 187-209.

Searle, J. R. (1969). Speech Acts: An Essay in the Philosophy of Language. Cambridge, U.K.: Cambridge University Press.

Sordoni, A. (2008). Conception et implantation d'un agent artificial dans le cadre du projet SimParc. Rapport de stage de Master 2ème année, Master Intelligence Artificielle et Décision (IAD), Université Pierre et Marie Curie - Laboratoire d'Informatique de Paris 6, Paris, France, September.

Sordoni, A., \& Briot, J.-P., \& Alvarez, I., \& Vasconcelos, E., \& Irving, M. A., \& Melo, G. (2010). Design of a participatory decision making agent architecture based on argumentation and influence function - Application to a serious game about biodiversity conservation. RAIRO $-A n$ International Journal on Operations Research, 44(4), 269-284.

Vasconcelos, E., \& Briot, J.-P., \& Irving, M. A., \& Barbosa, S., \& Furtado, V. (2009a). A user interface to support dialogue and negotiation in participatory simulations. In N. David and J. S. Sichman (Eds.), Multi-Agent-Based Simulation IX, LNAI 5269, Springer-Verlag, pp. 127-140.

Vasconcelos, E., \& Melo, G., \& Briot, J.-P., \& Patto, V. S., \& Sordoni, A., \& Irving, M. A., \& Alvarez, I., \& Lucena, C. (2009b). A serious game for exploring and training in participatory management of national parks for biodiversity conservation: Design and experience. In Proceedings of the VIII Brazilian Symposium on Games and Digital Entertainment (SBGAMES'09), Rio de Janeiro, Brazil, October, pp. 93-100.

Wall, J. A., \& Blum, M. W. (1991). Negotiations. Journal of Management, 17(2), 273-303.

Wei, W., \& Alvarez, I., \& Martin, S., \& Briot, J.-P., \& Irving, M. A., \& Melo, G. (2012). Integration of viability models in a serious game for the management of protected areas. In A. Palma dos Reis, P.S.P. Wang and A.P. Abraham (Eds.), Proceedings of the IADIS Intelligent Systems and Agents Conference (ISA'2012), Lisboa, Portugal, July, pp. 55-62. 
Wei, W., \& Alvarez, I., \& Martin, S. (2013). Sustainability analysis: Viability concepts to consider transient and asymptotical dynamics in socio-ecological tourism-based systems. Ecological Modelling, 251, 103-113. 


\section{KEY TERMS AND DEFINITIONS}

Agent: An autonomous software entity being able to take decision and action (including communication with other agents).

Assistant agent: An artificial agent dedicated to help and assist a human user.

Expert agent: An artificial agent to assist game players with technical expertise.

Multi-agent system: An organization of interacting agents.

National parks: A type of protected areas where there cannot be direct use of resources.

Park manager agent: An artificial agent which models the decision behavior of the manager of a national park.

Protected area: A geographically delimited area where public policies of biodiversity conservation are conducted.

Role-playing game: A game where players play a certain role, partially reproducing a certain situation.

Serious game: A role-playing game intended for training and exploring participatory behaviors which incorporates computer support inspired by video games.

Stakeholder: A social actor who is concerned by the public policy. Examples of stakeholders for a national parks are: traditional population, environmental $\mathrm{ONG}$, tourism operator.

Viability: A mathematical formalism for modeling the policies that can retain or restore desirable properties of a dynamical system (biological, economical...). 